\title{
cAMP-Dependent Enhancement of Dihydropyridine-Sensitive Calcium Channel Availability in Hippocampal Neurons
}

\author{
Ege T. Kavalali, Katherine S. Hwang, and Mark R. Plummer \\ Department of Biological Sciences, Rutgers University, Piscataway, New Jersey 08855-1059
}

Dihydropyridine-sensitive calcium channels can be strongly modulated by cAMP-dependent phosphorylation. This modulation takes the form of increased channel availability in cardiac myocytes (for review, see McDonald et al., 1994) and has been suggested to be essential for voltage-dependent facilitation in adrenal chromaffin cells (Artalejo et al., 1992) and skeletal muscle (Sculptoreanu et al., 1993b). To determine the role of cAMPdependent phosphorylation on dihydropyridine-sensitive calcium channels in hippocampal neurons, we have used both single-channel and whole-cell recording techniques and have examined the effects of the membrane-permeable cAMP analog 8-(4-chlorophenylthio) (CPT)-cAMP and the protein kinase inhibitors 1-(5-isoquinolinesulfonyl)-2-methylpiperazine $(\mathrm{H}-7)$ and $\mathrm{N}$-[2-( $p$-bromocinnamyl-amino)ethyl]-5-isoquinolinesulfonamide $(\mathrm{H}-89)$.

Hippocampal neurons contain two kinds of dihydropyridinesensitive calcium channel activity: Ls and Lp (Kavalali and
Plummer, 1994). The Ls channel closely resembles the cardiac L-type channel, whereas the Lp channel shows a novel lowvoltage form of voltage-dependent potentiation (Kavalali and Plummer, 1996). 8-CPT-cAMP increased the availability of both the Ls and Lp channels and caused a parallel increase in Lp channel reopenings at the repolarization potential that result from voltage-dependent potentiation. This effect was completely blocked by the broad spectrum kinase inhibitor $\mathrm{H}-7$ and by the protein kinase A-specific inhibitor $\mathrm{H}-89$. The two inhibitors, however, did not disrupt baseline potentiation of the Lp channel, suggesting that cAMP-dependent protein kinase activity can enhance Ls and Lp channel activity but is not required for voltage-dependent potentiation in hippocampal neurons.

Key words: calcium channel; hippocampus; potentiation; phosphorylation; facilitation; dihydropyridine; cAMP; protein kinase $\mathrm{A}$; $\mathrm{H}-7$; $\mathrm{H}-89$
Voltage-gated calcium channels, key regulators of calcium entry into cells, are subject to extensive modulation. For example, L-type calcium channels in cardiac cells show enhanced activity after application of $\beta$-adrenergic agonists, an effect mediated by cAMP-dependent protein kinase A (PKA), which leads to increased strength of muscle contraction (for review, see McDonald et al., 1994). Neuronal N-type channel activity is decreased by neurotransmitters (for review, see Anwyl, 1991), which can have the functional consequence of presynaptic inhibition (Scholz and Miller, 1991; Toth et al., 1993). N-type channel inhibition is mediated by G-protein-coupled receptors, and the actions of neurotransmitters can be blocked by agents such as pertussis toxin or GDP- $\beta$-S (for review, see Hille, 1994).

Another form of modulation is voltage-dependent potentiation of calcium channel activity in which conditioning prepulses dramatically enhance the responsiveness of calcium channels to subsequent test pulses. First studied using whole-cell recording from adrenal chromaffin cells (Fenwick et al., 1982), the potentiation was described as an alteration in the gating of a dihydropyridine (DHP)-sensitive channel in which prolonged tail currents were seen after a large depolarization (Hoshi and Smith, 1987). Subsequent reports referred to the phenomenon as

Received Jan. 24, 1997; revised May 5, 1997; accepted May 7, 1997.

Supported by National Institutes of Health Grant NS 34061. We are grateful to Dr. R. L. Davis for helpful discussions and comments on this manuscript.

Correspondence should be addressed to Mark R. Plummer, Department of Biological Sciences, Rutgers University, Nelson Lab, Busch Campus, Piscataway, NJ 08855-1059.

Dr. Kavalali's present address: Department of Molecular and Cellular Physiology, Beckman Center, Stanford University Medical Center, Stanford, CA 94305.

Copyright (C) 1997 Society for Neuroscience $0270-6474 / 97 / 175334-15 \$ 05.00 / 0$ voltage-dependent facilitation and suggested instead that the enhanced calcium current was attributable to recruitment of a normally silent DHP-sensitive channel type (Artalejo et al., 1991a,b). Voltage-dependent facilitation of non-DHP-sensitive channels, attributed to a voltage-dependent relief of G-protein inhibition, has also been described (Elmslie et al., 1990; Ikeda, 1991; Kasai, 1991).

A detailed investigation of the mechanism of calcium channel potentiation in adrenal chromaffin cells suggested that the process was not intrinsic to the channel and required the involvement of an unknown protein kinase (Artalejo et al., 1992). This same mechanism has also been posited to apply to skeletal muscle calcium channels (Sculptoreanu et al., 1993b) and cardiac calcium channel $\alpha_{1}$ subunits (Sculptoreanu et al., 1993a), although the result is somewhat controversial (Foley and Pelzer, 1994; Kleppisch et al., 1994).

In hippocampal neurons, we have recently described voltagedependent potentiation of DHP-sensitive calcium channels (Kavalali and Plummer, 1994). One kind of channel, Ls, shows prolonged openings after large depolarizing pulses (Kavalali and Plummer, 1996) that strongly resemble the potentiation described for cardiac L-type channels (Pietrobon and Hess, 1990). This high-voltage potentiation (HVP) is also shown by a second kind of DHP-sensitive channel, Lp. In addition to HVP, the Lp channel shows a different kind of potentiation characterized by bursts of reopenings at the repolarization potential after relatively modest depolarizations (Kavalali and Plummer, 1996). This low-voltage potentiation (LVP) is found exclusively in $\mathrm{Lp}$ channels.

In this paper we have characterized the effect of cAMP- 
dependent protein kinase activity on Ls and Lp channels. We show that both Ls and Lp channels are subject to extrinsic modulation by PKA, manifested as an increase in channel availability. We found, however, that the low- and high-voltage forms of potentiation are insensitive to protein kinase inhibitors and thus may be intrinsic to the channel.

\section{MATERIALS AND METHODS}

For single-channel recordings, hippocampal neurons were obtained from embryonic day 18 Sprague Dawley rats and were plated on Falcon Primaria dishes at a final density of $10^{6}$ cells per dish. Cultures were prepared according to the method of $\mathrm{Lu}$ et al. (1991) and maintained in serum-free medium (SFM) at $37^{\circ} \mathrm{C}$ in a $95 \%$ air $/ 5 \% \mathrm{CO}_{2}$ humidified incubator. SFM consisted of a 1:1 (v/v) mixture of Ham's F-12 and Eagle's minimum essential medium and supplemented with insulin (25 $\mu \mathrm{g} / \mathrm{ml})$, transferrin $(100 \mu \mathrm{g} / \mathrm{ml})$, putrescine $(60 \mu \mathrm{M})$, progesterone $(20$ $\mathrm{nM})$, selenium (30 nM), glucose $(6 \mathrm{mg} / \mathrm{ml})$, and penicillin-streptomycin $(0.5 \mathrm{U} / \mathrm{ml}$ and $0.5 \mathrm{mg} / \mathrm{ml}$, respectively). Recordings were performed 3-10 $\mathrm{d}$ after dissociation.

For whole-cell recordings, an acute dissociation technique, based on the method described by Johnson and Byerly (1994), was used. Hippocampi from 7- to 16-d-old Sprague Dawley rats were removed rapidly and cut into 300- to 400- $\mu \mathrm{m}$-thick slices using a McIlwain tissue chopper (Brinkmann Instruments, Westbury, NY). These slices were incubated at $35^{\circ} \mathrm{C}$ in PIPES saline (in mM: $120 \mathrm{NaCl}, 5 \mathrm{KCl}, 1 \mathrm{CaCl}_{2}, 1 \mathrm{MgCl}_{2}, 20$ PIPES, and 25 glucose, $\mathrm{pH} 7.0)$ with added protease $(2 \mathrm{mg} / \mathrm{ml}$; type XIV Sigma, St. Louis, MO) for 10 min and continuously bubbled with medical grade oxygen. Tissue slices were later rinsed in the PIPES saline without protease and placed into a scintillation vial, where they were constantly stirred in an $\mathrm{O}_{2}$ atmosphere. As needed, hippocampal neurons were triturated onto poly-L-lysine-coated Petri dishes in the PIPES saline without protease. Neurons prepared this way were viable for up to $5 \mathrm{hr}$, and they had few or no processes, making them suitable for voltage clamp. To date, single-channel recordings from acutely dissociated cells have revealed no differences in the properties of $\mathrm{Lp}$ channels compared with those obtained from embryonic neurons. The lower channel density in the embryonic neurons, however, makes them more favorable for single-channel experiments.

Cell-attached single-channel recordings were made with barium as the charge carrier (in mM): $110 \mathrm{BaCl}_{2}$ and 10 HEPES-TEAOH, pH 7.5, and a depolarizing external recording solution was used to bring the intracellular potential to $\sim 0 \mathrm{mV}$ (in $\mathrm{mM}$ ): 140 potassium gluconate, 10 HEPES-KOH, and 5 EGTA, $\mathrm{pH}$ 7.5. Unless otherwise specified, $0.1 \mu \mathrm{M}$ DHP agonist $(+)-(S)-202-791$ (a gift from Sandoz, Basel, Switzerland) was added to the bath solution to clarify the number and types of calcium channels in the patch. Recordings were made with an Axopatch 200 amplifier (Axon Instruments, Foster City, CA). Data were sampled with an INDEC Systems (Capitola, CA) 15125 analog-to-digital converter at $5 \mathrm{kHz}$ and filtered at $1 \mathrm{kHz}$. Eight hundred millisecond voltage pulses (typically 160, 320, and $320 \mathrm{msec}$ at holding, test, and holding potentials, respectively) were delivered at $5 \mathrm{sec}$ intervals. Linear leak and capacitative currents were subtracted digitally. All recording parameters were controlled by programs written in Borland $\mathrm{C}^{++}$using INDEC-supplied driver libraries.

Whole-cell recordings were made with barium as the charge carrier (in $\mathrm{mM}$ ): $20 \mathrm{BaAc}_{2}$, 135 TEACl, 0.001 TTX, and 10 HEPES, pH 7.4. The pipette contained (in $\mathrm{mM}$ ) 108 cesium methanesulfonate, $4 \mathrm{MgCl}_{2}, 9$ EGTA, 9 HEPES, 4 MgATP, 14 creatine phosphate, $0.3 \mathrm{Na}_{3} \mathrm{GTP}, 50$ $\mathrm{U} / \mathrm{ml}$ creatine phosphokinase, $\mathrm{pH}$ 7.4. Series resistances were 7-9 $\mathrm{M} \Omega$ before compensation. All experiments were carried out at room temperature. Data were sampled at $10 \mathrm{kHz}$ and filtered at $5 \mathrm{kHz}$. Four hundred millisecond msec voltage pulses (typically 80, 80, and $240 \mathrm{msec}$ at holding, test, and holding potentials, respectively) were delivered at $4 \mathrm{sec}$ intervals. Leak currents were measured with hyperpolarizing pulses to $1 / 10$ of the step potential.

Open times and open probabilities were obtained from sweeps idealized with a half-amplitude crossing criterion and cubic spline interpolation (Colquhoun and Sigworth, 1983). Incomplete openings, such as tail current openings, were excluded from analysis. Values were plotted on square root-log coordinates, and mean open times were estimated from maximum likelihood fitting (Sigworth and Sine, 1987). Open times were evaluated in two ways. The first was to average values obtained from individual experiments for the purposes of statistical comparison. In Results, these data are presented as averages \pm SEM. The second method was to sum data from all experiments and treat it as a single distribution. This gave us the best quality fit, and extracted values are presented in the figures as individual open times. The summed distributions were compared statistically with the Kolmogorov-Smirnov test. Overall open probability was calculated by evaluating activity for the entire recording, including null sweeps. A conditional open probability was also calculated after exclusion of null sweeps. For patches that contained two of the same kind of channel, open probability was measured for both channels and divided by two. Similarly, null sweep probability was calculated by taking the square root of the proportion of null sweeps. This assumes that the two channels have similar but independent gating characteristics and gives values appropriate for a single channel. Unless otherwise stated, statistical comparisons were made with Student's $t$ test. Data analysis was accomplished by programs written in Microsoft Visual Basic.

Lp and Ls channels were identified according to criteria described previously (Kavalali and Plummer, 1994). In brief, Lp activity was identified by the presence of reopenings during repolarization to -40 $\mathrm{mV}$ after a voltage pulse to $+20 \mathrm{mV}$. When studied in the presence of the DHP agonist (+)-202-701, Lp channels could be further distinguished from Ls channels on the basis of unitary current amplitude and relatively shorter open times. Three kinds of recordings were selected for detailed analysis. The first was from patches that contained only a single channel, evidenced by total absence of superimposed openings during a recording of at least $20 \mathrm{~min}$ in duration. Patches of this type were encountered relatively infrequently, although they yielded the most useful information. The second was from patches that contained two of the same kind of channel, determined by the presence of superimposed openings of a single type. Patches that seemed to contain three of the same kind of channel were not used. The third type of recording was from multichannel patches that contained both Lp and Ls channels (typically one to three Ls and one or two Lp channels). These patches were used exclusively for studies of $L p$ potentiation, because only $L p$ channels are active after repolarization to $-40 \mathrm{mV}$ (Kavalali and Plummer, 1994). Patches containing non-DHP-sensitive channels (e.g., T-, N-, and P-type channels, which typically showed more openings when tested from a holding potential of $-90 \mathrm{mV}$ compared with $-40 \mathrm{mV}$ ) were not used.

Unless otherwise specified, all chemicals were obtained from Sigma. Drugs were applied by preincubation for at least $30 \mathrm{~min}$ while the cells were still in the humidified incubator and were also added to the extracellular recording solution. 1-(5-isoquinolinesulfonyl)-2-methylpiperazine (H-7) and $N$-[2-( $p$-bromocinnamyl- amino)ethyl]-5-isoquinolinesulfonamide $(\mathrm{H}-$ 89; Calbiochem, La Jolla, CA) were dissolved in DMSO and diluted 1:1000 and 1:10,000, respectively, in media for preincubation and bath solution for recording.

\section{RESULTS}

These experiments were designed (1) to characterize cAMPdependent modulation of hippocampal Lp and Ls calcium channels and (2) to determine whether voltage-dependent phosphorylation is required for $\mathrm{Lp}$ channel potentiation. The first aim was accomplished by measuring Ls and L p channel activity during a standard test pulse to $+20 \mathrm{mV}$ from a holding potential of -40 $\mathrm{mV}$ from cells in which we had directly stimulated PKA with the membrane-permeable cAMP analog 8-(4-chlorophenylthio) (CPT)-cAMP (1 mM). Recordings from these cells were compared with controls, which had received vehicle solution. The cAMP analog was applied by pretreating cells for a minimum of $30 \mathrm{~min}$ before recording. We chose the preincubation approach to examine effects of steady state cAMP elevation rather than observe the time course of the response. Because both Lp and Ls channels show considerable sweep-to-sweep variability, it was necessary to use conditions that allowed substantial data collection under stable conditions. Moreover, it is not always the case that receptor-activated second messengers can travel to areas underneath cell-attached recording pipettes (Forscher and Oxford, 1985; Lipscombe et al., 1989; Foehring, 1996), so we also avoided the potential problem of limited diffusion of 8-CPTcAMP. The results of this paper are based on $>200$ recordings of Lp and Ls channels, of which 121 were of sufficient durations to 

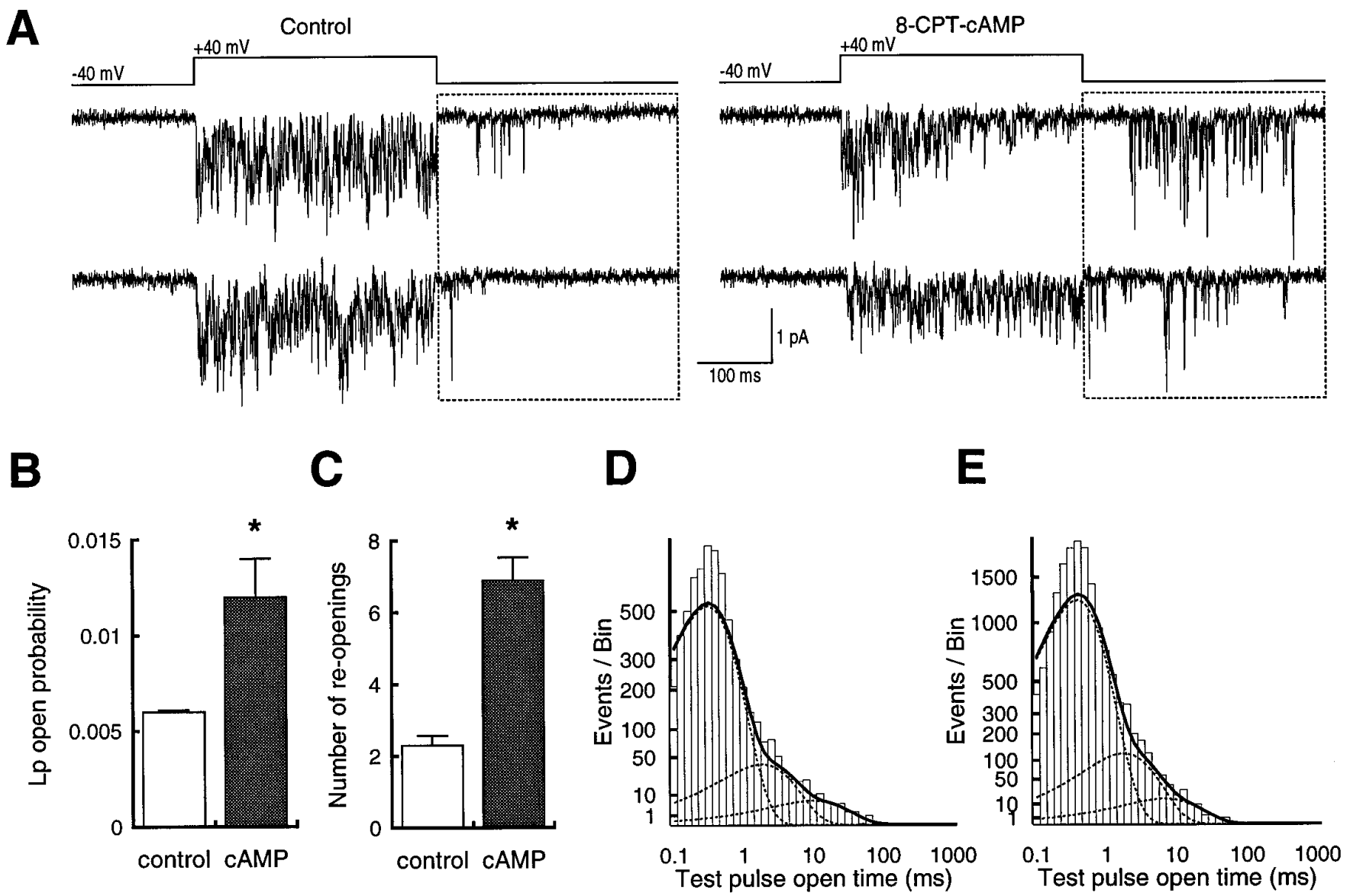

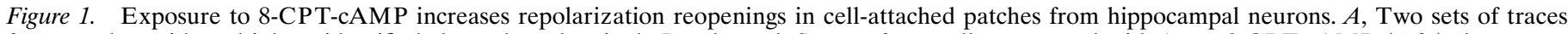

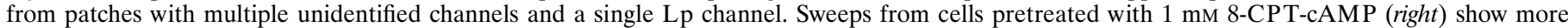

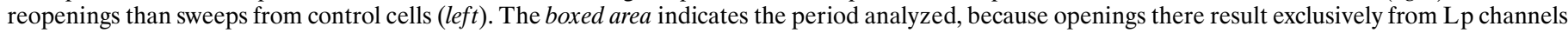

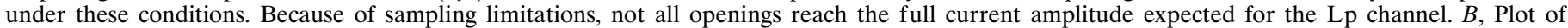

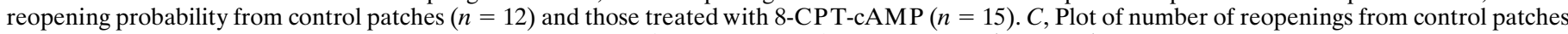

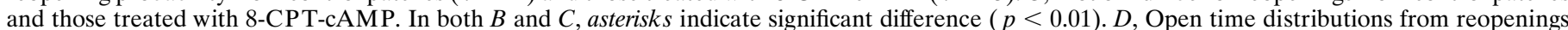

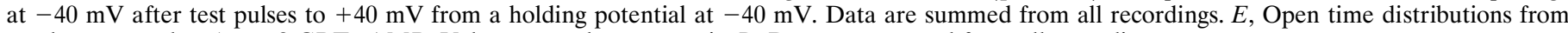
patches exposed to $1 \mathrm{mM}$ 8-CPT-cAMP. Voltages are the same as in D. Data are summed from all recordings.

be analyzed in detail. Of these, 20 were from patches that contained only a single Ls channel, 11 were from patches that contained two Ls channels, 8 were from patches that contained only a single $\mathrm{Lp}$ channel, and 1 was from a patch that contained two Lp channels. The remainder were multichannel recordings that contained no more than three Ls channels and one or two Lp channels.

The second aim, studies of Lp potentiation, was accomplished by quantifying activity during the $-40 \mathrm{mV}$ repolarization period in all recordings and during the $+20 \mathrm{mV}$ test pulse in patches with single channels. According to our working model, initial openings elicited by the $+20 \mathrm{mV}$ test pulse represent activation of the unpotentiated channel. At some time during the test pulse depolarization, the channel can enter a potentiated state in which its activation threshold is reduced. This results in the channel continuing to open even when the membrane voltage is returned to the holding potential of $-40 \mathrm{mV}$, a voltage that will not activate the unpotentiated channel. The Lp channel will then reopen at the holding potential until it reverts to its initial state. Thus, if voltage-dependent potentiation of the L $\mathrm{p}$ channel requires phosphorylation, it should be possible to enhance or eliminate repolarization reopenings with phosphorylation activators or inhibi- tors while preserving activity that results from the nonpotentiated state.

\section{cAMP-dependent modulation of Ls and Lp channels}

cAMP-dependent modulation of hippocampal calcium currents was examined with cell-attached single-channel recording to identify precisely the target and nature of the effects. Our initial recordings were made without DHP agonist, to ensure that $(+)-202-791$ did not alter calcium channel modulation. Under these conditions, we focused on channel openings that occurred during the repolarization period, because we have previously shown that these result exclusively from L p channels at a holding potential of $-40 \mathrm{mV}$ (Kavalali and Plummer, 1994). Although the openings were brief and not completely resolved, we were able to identify a clear enhancement of $\mathrm{Lp}$ channel activity in recordings obtained from cells that had been pretreated with $1 \mathrm{~mm}$ 8-CPT-cAMP (Fig. $1 A$ ).

To compare Lp channel activity from control and 8-CPTcAMP-treated cells, we selected patches that contained only a single Lp channel. Our criteria for this determination in the absence of fully resolved openings was to use the predicted current amplitude of the open channel at $-40 \mathrm{mV}$ and to discard 
patches that contained openings larger than this value. To examine the reliability of this method, DHP agonist was applied at the end of the recording to prolong the open time and to allow accurate assessment of the number of channels in the patch. In four of four recordings examined in this fashion, only a single $\mathrm{Lp}$ channel was present in the patch.

From these experiments, we measured open probability during the repolarization period ("reopening probability") and counted the number of openings. For both measures, 8-CPT-cAMP caused a greater than twofold enhancement of $\mathrm{Lp}$ channel activity (Fig. $1 B, C$ ). We also calculated mean open time from these patches but did not find a difference between the control and 8-CPT-cAMP-treated cells (Fig. 1D,E). Because of the long observation times required, the sampling interval used did not adequately capture submillisecond open times. Thus the fitted distributions are not accurate for the briefest openings. Nonetheless, the method was sufficient for longer openings, and the absence of apparent differences suggested that 8-CPT-cAMP increased reopening probability by enhancing channel availability rather than mean open time.

To obtain more dependable estimates of the number of channels in a patch, as well as to optimize conditions for quantitative analysis, subsequent experiments were done in the presence of the DHP agonist (+)-202-791. As in the absence of DHP, patches exposed to 8-CPT-cAMP showed increased activity of DHPsensitive calcium channels when compared with control patches that contained the same kinds and numbers of channels (Fig. 2). Enhanced activity was evident both during a test pulse of $+20 \mathrm{mV}$ and after repolarization to $-40 \mathrm{mV}$. Inspection of individual traces suggested that both Ls and Lp channel types were affected. Lp channel activity can be seen as reopenings during the repolarization. The longest duration openings, especially visible in the traces from the cell treated with the cAMP analog, represent activity of the Ls channel. The effect of the 8-CPT-cAMP was clear in average currents, which showed a doubling of magnitude. Examination of tail currents, in which Lp activity predominates at these voltages (Kavalali and Plummer, 1996), showed an increase in the frequency of sweeps with reopenings.

Although multichannel recordings provided evidence of increased activity in response to application of 8-CPT-cAMP, two issues needed to be resolved. First, the simultaneous Ls and Lp openings made it difficult to determine the nature of the effects on the individual channel types. Second, to address voltagedependent potentiation, it was necessary to measure L p activity during the test pulse and during repolarization independently. To answer these questions, we analyzed in detail recordings from patches that contained either a single channel, or two of the same kind of channel (Figs. 3, 4).

\section{Ls channels}

Comparisons of single Ls channel patches from control and pretreated cells showed an obvious increase in activity in cells exposed to 8-CPT-cAMP (Fig. 3A). This difference was statistically significant for open probability $\left(p_{\mathrm{o}}\right)$ between control cells $(0.1 \pm 0.02 ; n=10)$ and 8-CPT-cAMP-treated cells $(0.35 \pm 0.05$; $n=11 ; p<0.001$; Fig. $3 B$ ). To gain some insight into the mechanism of the effect, we measured both the frequency of sweeps with no openings (null sweeps) and mean dwell times in open states. The probability of null sweeps declined in cells treated with 8-CPT-cAMP $(0.093 \pm 0.015)$ compared with controls $(0.42 \pm 0.06$; Fig. $3 C)$. This was not accompanied, however, by a significant change in the prominent components of mean open time. For Ls channels, best fits to the data were obtained with three-exponential functions. Control recordings showed average mean open times of $0.93 \pm 0.26,6.34 \pm 0.8$, and $44.1 \pm 13.5$ msec compared with $0.68 \pm 0.06,8.14 \pm 0.96$, and $24.9 \pm 4.9 \mathrm{msec}$ for cells treated with 8-CPT-cAMP $(p>0.2,0.1$, and 0.1 , respectively). Summed data from all recordings also did not show any significant differences between control and cAMP conditions (Figs. 3D,E; $p>0.05$, Kolmogorov-Smirnov test).

\section{Lp channels}

Recordings from single Lp channels showed that 8-CPT-cAMP increased activity both during the test voltage pulse and the repolarization period (Fig. 4). According to our model, the repolarization reopenings represent activity of the potentiated $\mathrm{Lp}$ channel, and they cease once the Lp channel leaves this potentiated state or set of states. Openings observed during the test pulse, however, are initially caused by activity of the unpotentiated channel, which then makes a transition to the potentiated state. Therefore, test pulse and repolarization openings represent the onset and decay of potentiation, respectively, and we analyzed the two kinds of activity separately. Inspection of individual traces again suggested that the effect of 8-CPT-cAMP was largely attributable to an increased number of sweeps with activity, as well as an increased number of openings, but was not attributable to changes in the characteristics of the openings or independent effects on test pulse or repolarization activity (Fig. 4).

Analysis of openings during the test pulse showed a significant increase in overall open probability for cells exposed to the 8-CPT-cAMP $(0.13 \pm 0.03 ; n=3)$ compared with patches from control cells $(0.039 \pm 0.01 ; n=3 ; p<0.05$; Fig. $4 B)$. As with the Ls channel, there was a concomitant decrease in the probability of null sweeps $(0.5 \pm 0.035$ vs $0.15 \pm 0.07 ; p<0.05$; Fig. $4 C)$ but little change in open times obtained from summed data for all experiments (control, 0.82, 3.4, and $22.9 \mathrm{msec}$; cAMP, 0.78, 3.1, and $13.2 \mathrm{msec} ; p>0.05$, Kolmogorov-Smirnov test; Figs. 4D,E). Statistical comparisons of open times extracted from individual recordings also showed no significant differences between mean open times for controls $(0.99 \pm 0.23,3.8 \pm 0.4$, and $24.7 \pm 3.7$ msec) and cAMP-treated cells $(0.86 \pm 0.23,3.4 \pm 0.4$, and $19.6 \pm$ $4.8 ; p>0.7,0.5$, and 0.4 , respectively) or for their relative proportions in control $(0.79 \pm 0.04,0.21 \pm 0.04$, and $0.007 \pm$ $0.004 \mathrm{msec})$ and cAMP-treated cells $(0.63 \pm 0.09,0.35 \pm 0.09$, and $0.01 \pm 0.005 ; p>0.2,0.2$, and 0.6 , respectively). Comparison of the distributions of summed data were also not significantly different (Figs. 4D,E; $p>0.05$, Kolmogorov-Smirnov test).

The activity of L p channels during the repolarization period paralleled that seen during the test pulse when cells were exposed to 8-CPT-cAMP. Overall open probability increased (Fig. $4 F$ ), and the probability of null sweeps (sweeps with no reopenings) decreased (Fig. $4 G)$. Each of the effects was significant $(p<0.05)$. As with the test pulse results, there were no large changes in the magnitudes or distributions of open times in the individual data (control, $1.36 \pm 0.47,4.4 \pm 0.7$, and $27.6 \pm 9.8 \mathrm{msec}$; cAMP, $1.18 \pm 0.34,6.3 \pm 0.5$, and $33.9 \pm 6.9 \mathrm{msec} ; p>0.7,0.08$, and 0.6, respectively). No differences were apparent in the summed data either in the values of open time (control, 1.6, 4.9, and $24.5 \mathrm{msec}$; cAMP, $1.27,5.2$, and $31.6 \mathrm{msec}$ ) or in the shape of the distributions (Figs. 4H,I; $p>0.05$, Kolmogorov-Smirnov test).

We also analyzed closed times during the repolarization period but found no differences between the distributions obtained from summing the control and 8-CPT-cAMP data $(p>0.05$, Kolmogorov-Smirnov test). For both sets of cells, the briefest closures 

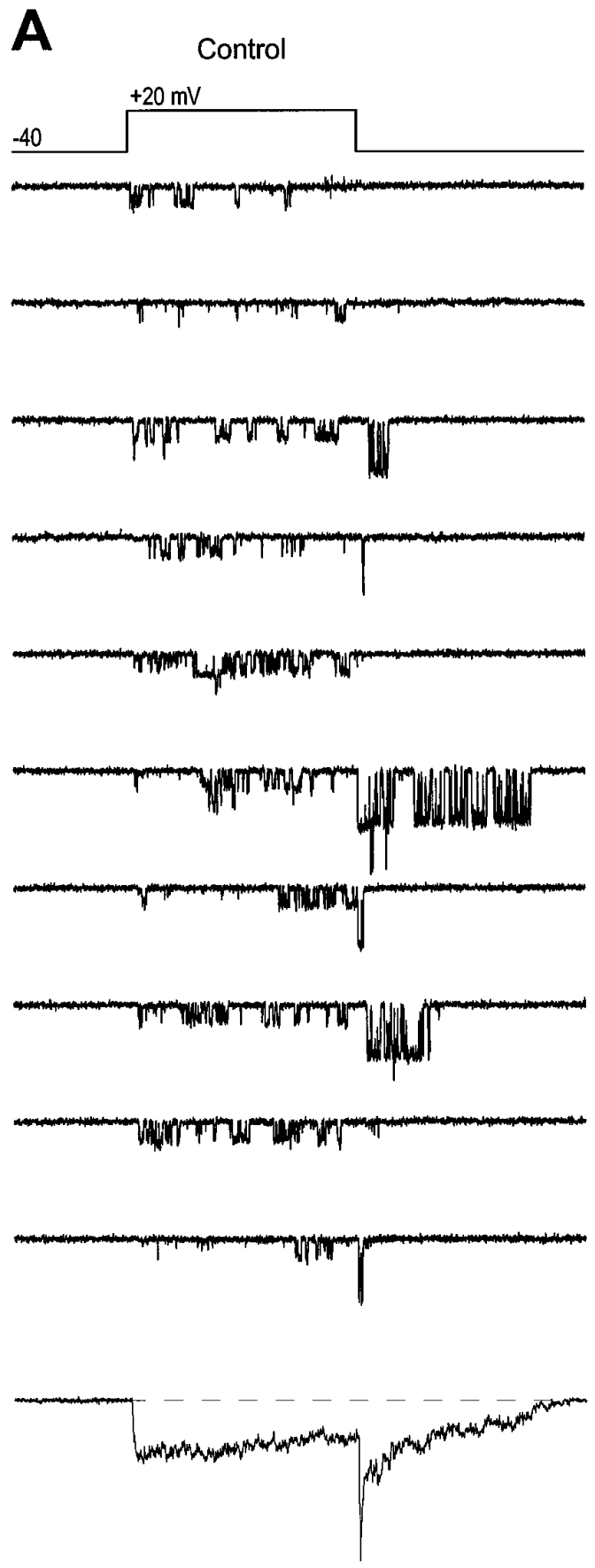
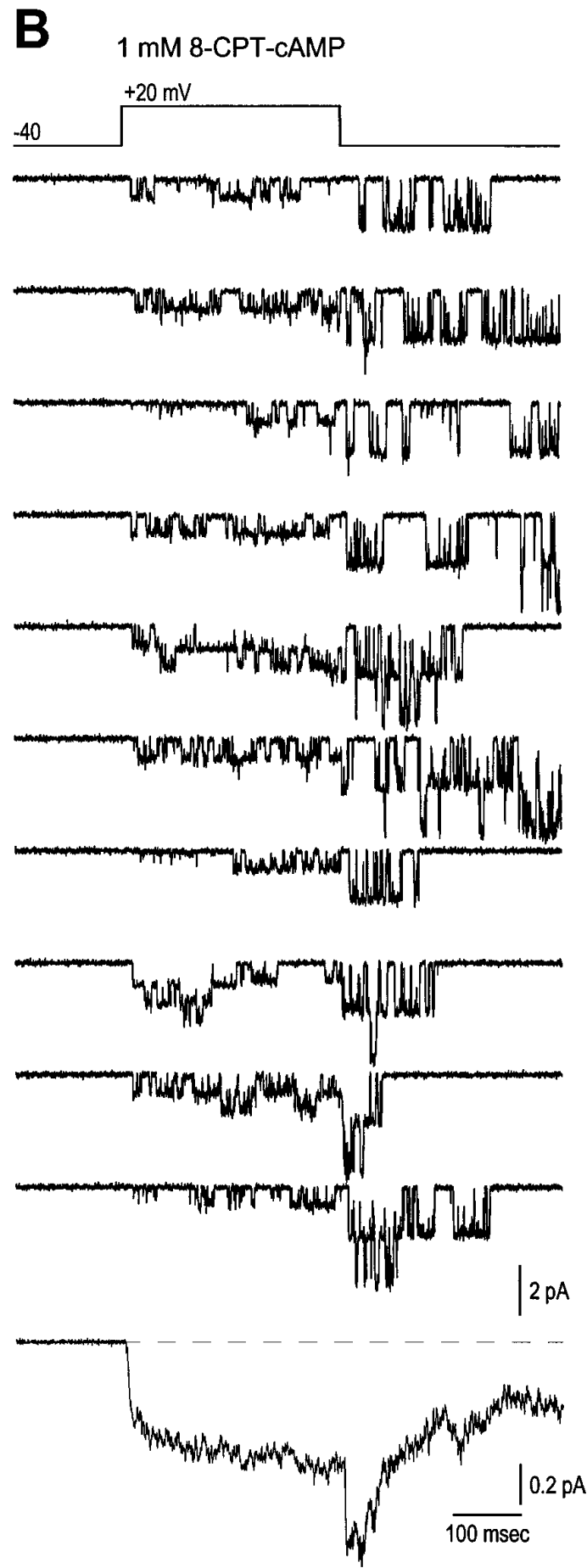

Figure 2. 8-CPT-cAMP enhances calcium channel activity in cell-attached patches. $A$, Ten consecutive sweeps from a patch with one Ls and two Lp channels. In this and all subsequent figures, the DHP agonist $(+)-(S)-202-791$ is in the bath $(0.1 \mu \mathrm{M})$. Lp channel reopenings can be seen in (from top) traces $3,4,6-8$, and $10 . B$, Ten consecutive sweeps from a patch with the same channel composition as in $A$. The cell was pretreated with 1 mM 8-CPT-cAMP. Lp reopenings are present in all traces. The bottom traces in both $A$ and $B$ are ensemble average currents from 114 and 100 sweeps, respectively.

were not well resolved, but three other components for controls $(0.69,8.1$, and $60.5 \mathrm{msec})$ and 8-CPT-cAMP cells $(0.68,9.9$, and $62.3 \mathrm{msec}$ ) were similar (data not shown).

To compare the magnitude of the 8-CPT-cAMP effect on test pulse activity with that seen during repolarization, we calculated the average charge transferred for each period. We used this approach because open probability does not take the differences in unitary current into account. At $-40 \mathrm{mV}, \mathrm{Lp}$ channel currents are almost three times larger than those seen at $+20 \mathrm{mV}$, thus providing substantial cation influx. Under control conditions, the average charge measured was $10.63 \pm 3.24$ femtocoulombs (fC) for the test pulse and $17.08 \pm 3.47 \mathrm{fC}$ for repolarization (data not 
A Ls channel
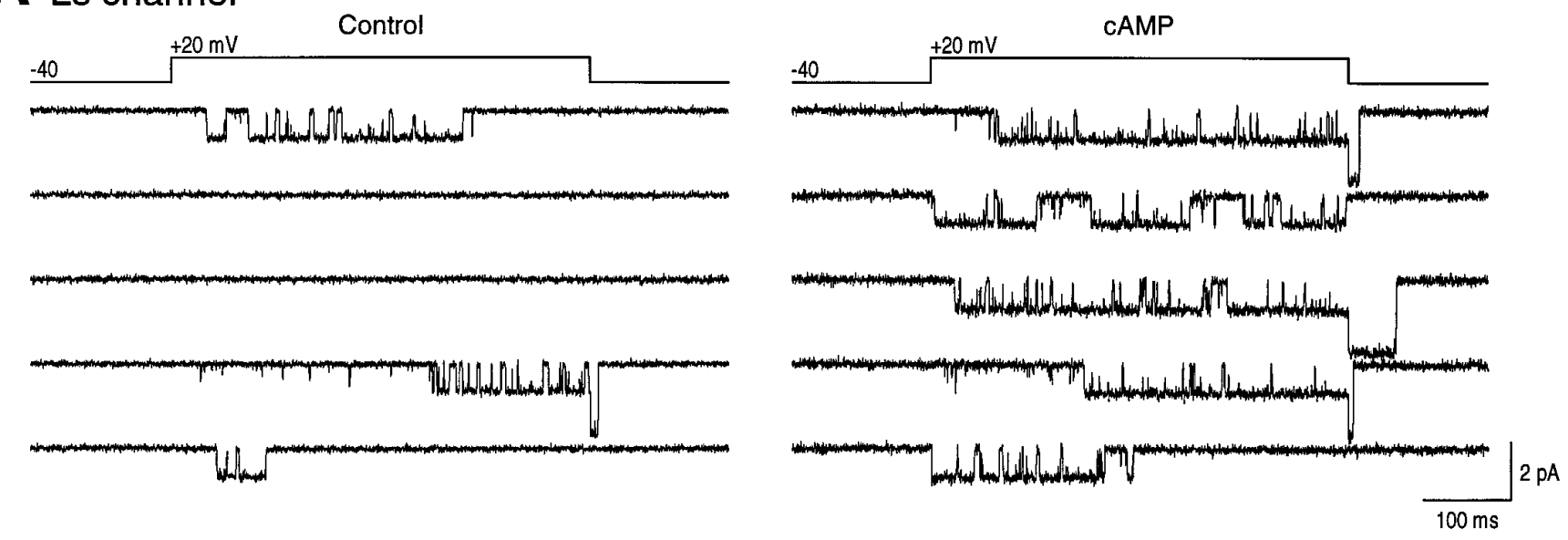

B

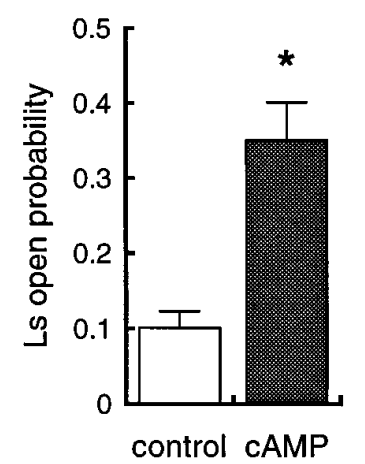

C

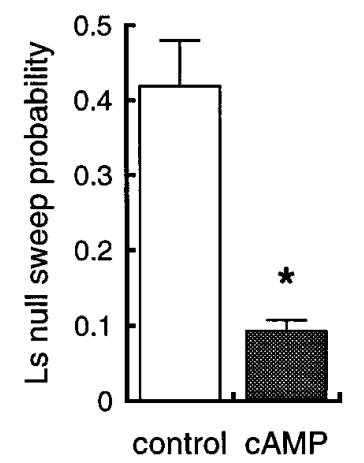

D
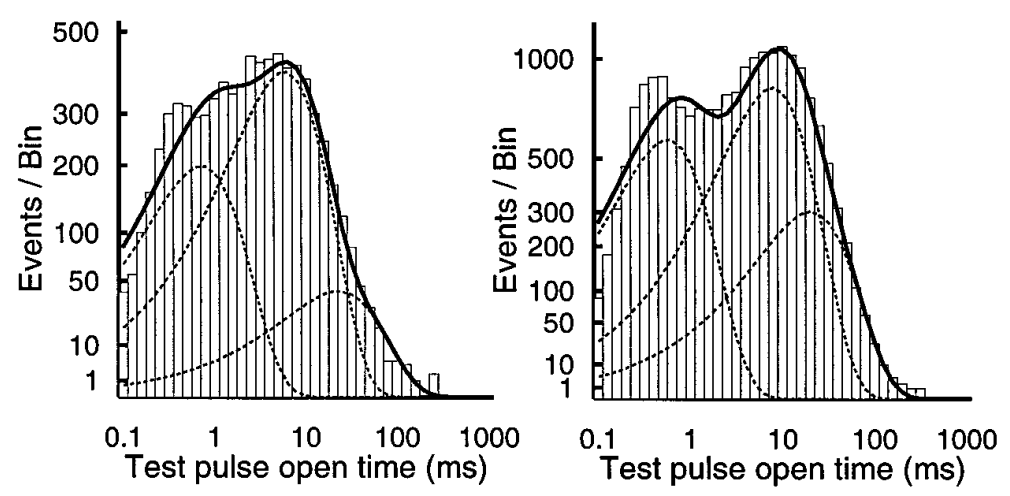

Figure 3. Recordings from patches containing single Ls channels showed increased activity after exposure to 8-CPT-cAMP. A, Two sets of five consecutive sweeps of Ls channel activity from a control patch $(l e f t)$ and one that had been pretreated with 1 mM 8-CPT-cAMP (right). Both patches contain only one Ls channel. $B$, Plot of $p_{\mathrm{o}}$ from control patches $(n=10)$ and those treated with 8-CPT-cAMP $(n=11)$. $C$, Plot of null sweep probability from control patches and those treated with 8-CPT-cAMP. In both $B$ and $C$, asterisks indicate significant difference $(p<0.001)$. $D$, Open time distributions from test pulses to $+20 \mathrm{mV}$ from a holding potential at $-40 \mathrm{mV}$. Data are summed from all recordings. $E$, Open time distributions from patches exposed to $1 \mathrm{mM} 8$-CPT-cAMP. Voltages are the same as in D. Data are summed from all recordings.

shown). In cells exposed to 8-CPT-cAMP, the amount of charge was increased for both test pulse and repolarization openings. Despite the lower open probability during repolarization, however, the amount of charge transferred during the two periods was almost identical, being $35.26 \pm 9.49 \mathrm{fC}$ for the test pulse and $32.16 \pm 3.52 \mathrm{fC}$ for repolarization (data not shown). Thus the enhanced activity produced by 8 -CPT-cAMP is equally significant during the voltage pulse and after it.

The above data suggest that the increased open probability seen in the presence of 8-CPT-cAMP could be entirely explained by the reduction in null sweeps. To examine this possibility, we grouped all control data and all 8-CPT-cAMP data and compared Lp channel reopening probability and the number of repolarization openings. When all sweeps were used, the difference between control and 8-CPT-cAMP was highly significant for both parameters. Reopening probability in 8-CPT-cAMP was $0.054 \pm 0.006$ compared with the control value of $0.02 \pm 0.003(n=18$ and 14 , respectively; $p<0.001$ ). Similarly, the average number of openings in cells treated with 8 -CPT-cAMP was $4.26 \pm 0.56$ compared with $1.67 \pm 0.3$ for controls $(p<0.01)$. If the differences were attributable to the decrease in null sweeps, then a conditional analysis in which null sweeps were excluded should make the control and
8-CPT-cAMP reopen probabilities and number of openings equal. This was not the case, however. Although the magnitude was smaller, differences in reopen probability (control, $0.049 \pm 0.007$; 8-CPT-cAMP, $0.077 \pm 0.007 ; p<0.01$ ) and numbers of openings (control, $4.62 \pm 0.61 ; 8-\mathrm{CPT}-\mathrm{cAMP}, 7.06 \pm 0.93 ; p<0.05$ ) were still significant.

\section{Phosphorylation dependence of Lp potentiation}

The preceding results suggested that cAMP-dependent protein kinase activity primarily increased Lp and Ls channel availability. Moreover, the similarity of the increase in Lp test pulse openings and reopenings suggested that the repolarization activity could be increased by, but may not require, cAMP. We explored this possibility further by studying $L \mathrm{p}$ channel activity in excised inside-out patches, with the assumption that this cell-free recording condition may disrupt the normal action of cytoplasmic kinases.

\section{Excised patches}

If potentiation depends on prepulse-induced phosphorylation, as suggested by work on adrenal chromaffin cells (Artalejo et al., 1992) and skeletal muscle (Sculptoreanu et al., 1993b), we hypothesized that excision of the patch could lead to a loss of reopenings 


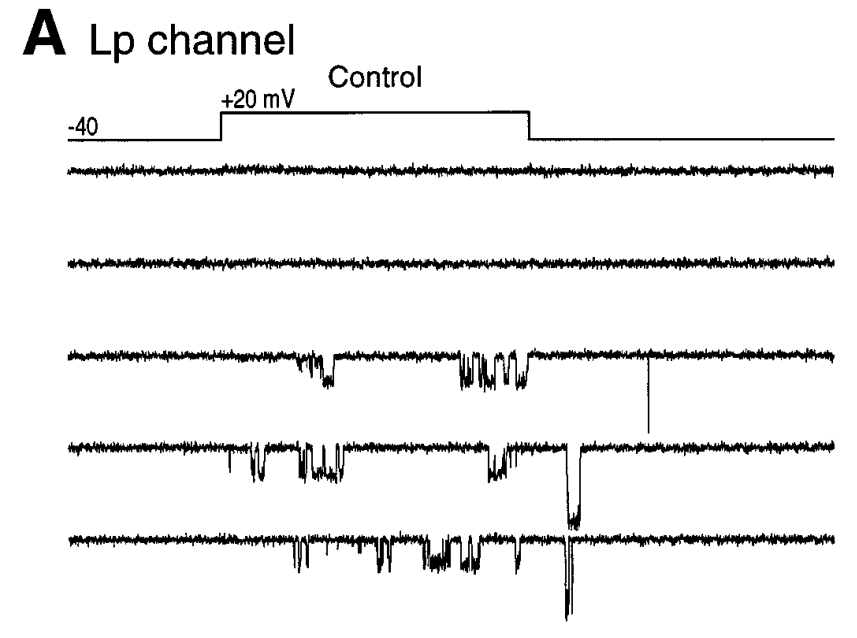

B

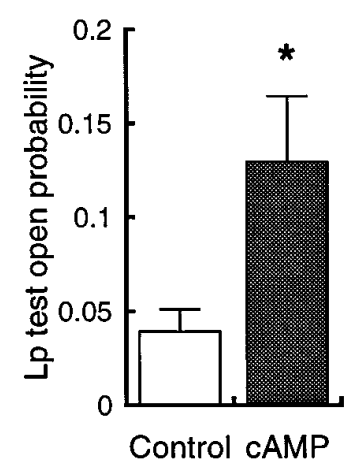

F

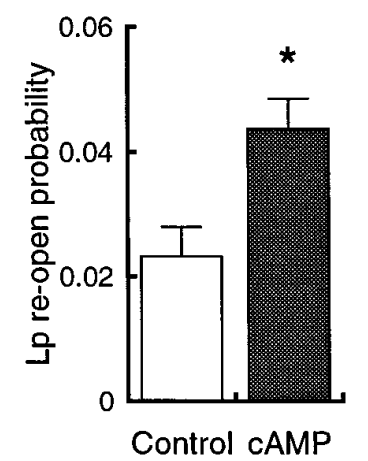

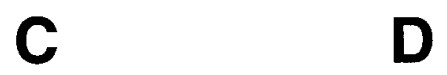

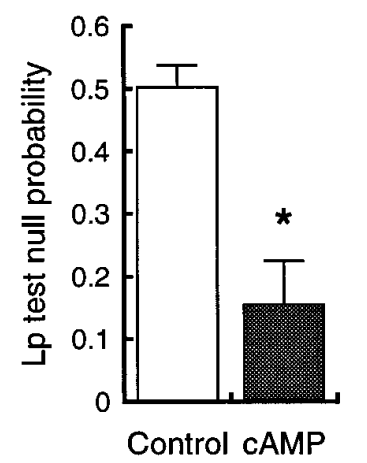

G

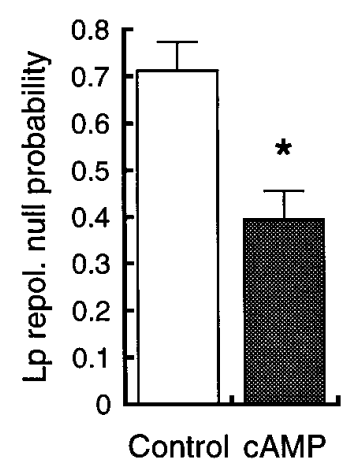

H

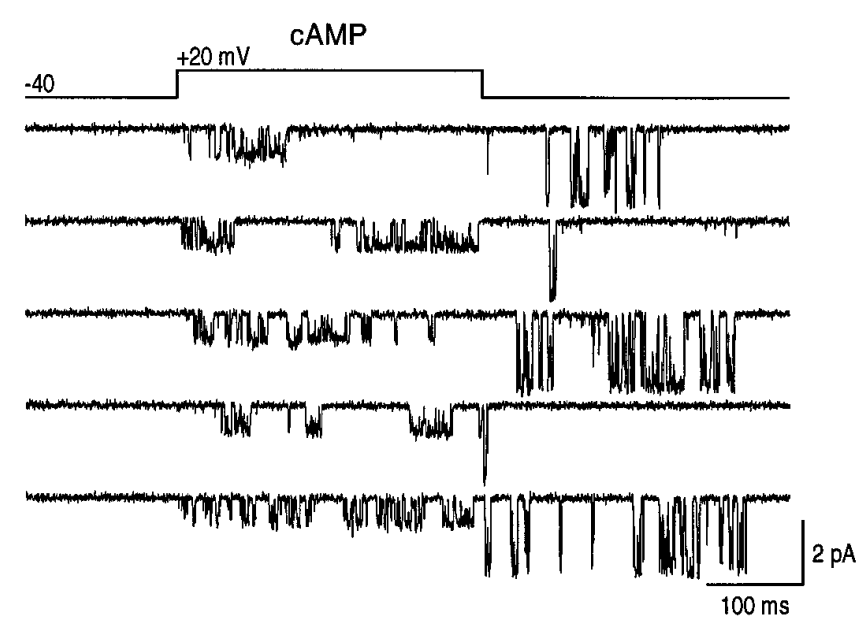

E
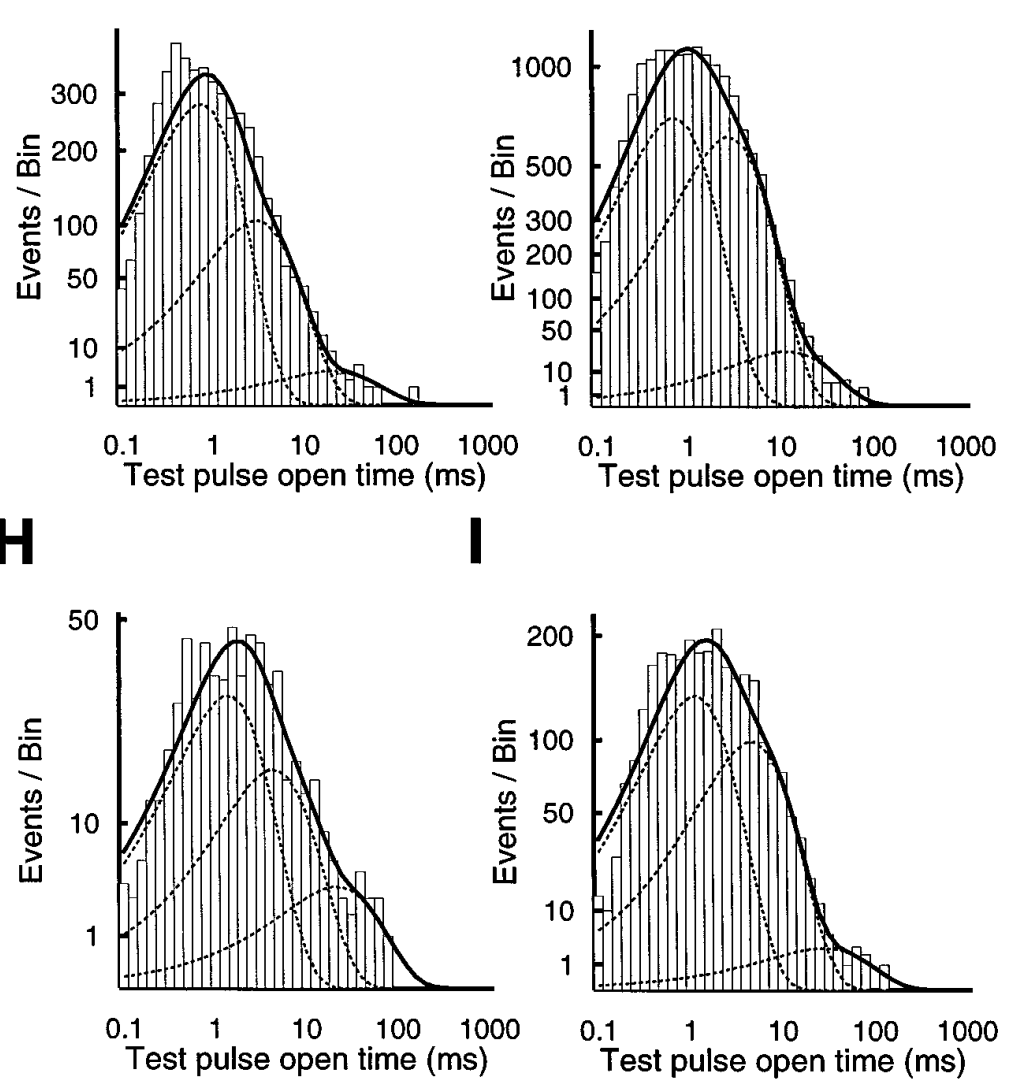

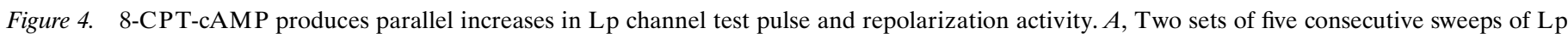

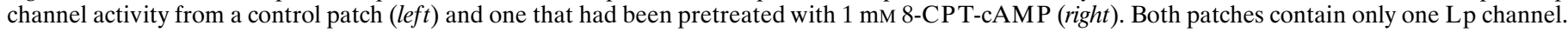

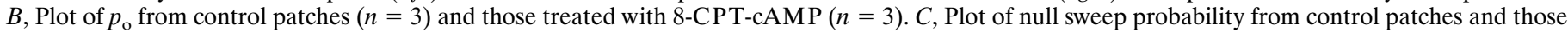

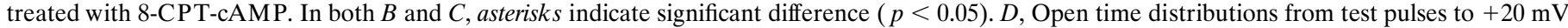

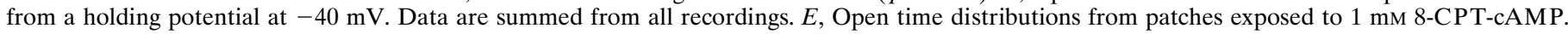

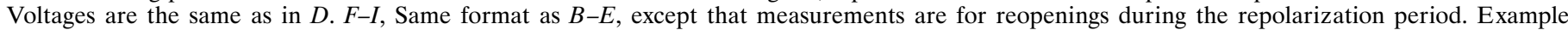
reopenings are seen in $A$ in (from top) traces 3-5 on the left and all traces on the right.

that would proceed independently of a reduction in test pulse openings. Initial multichannel recordings showed the expected rundown of Ls channels, but surprisingly, Lp channel reopenings persisted for the duration of the recording ( $n=5$; data not shown). Addition of $4 \mathrm{~mm} \mathrm{MgATP}$ did not prevent Ls channel rundown and had no effect on $\mathrm{Lp}$ channels in excised patches $(n=8)$. When examined in patches that contained only a single channel, excision did not uncouple $L p$ potentiation from activity during the test pulse (Fig. 5), and individual traces were indistinguishable before or many minutes after excision (Fig. 5A). 
A Lp channel
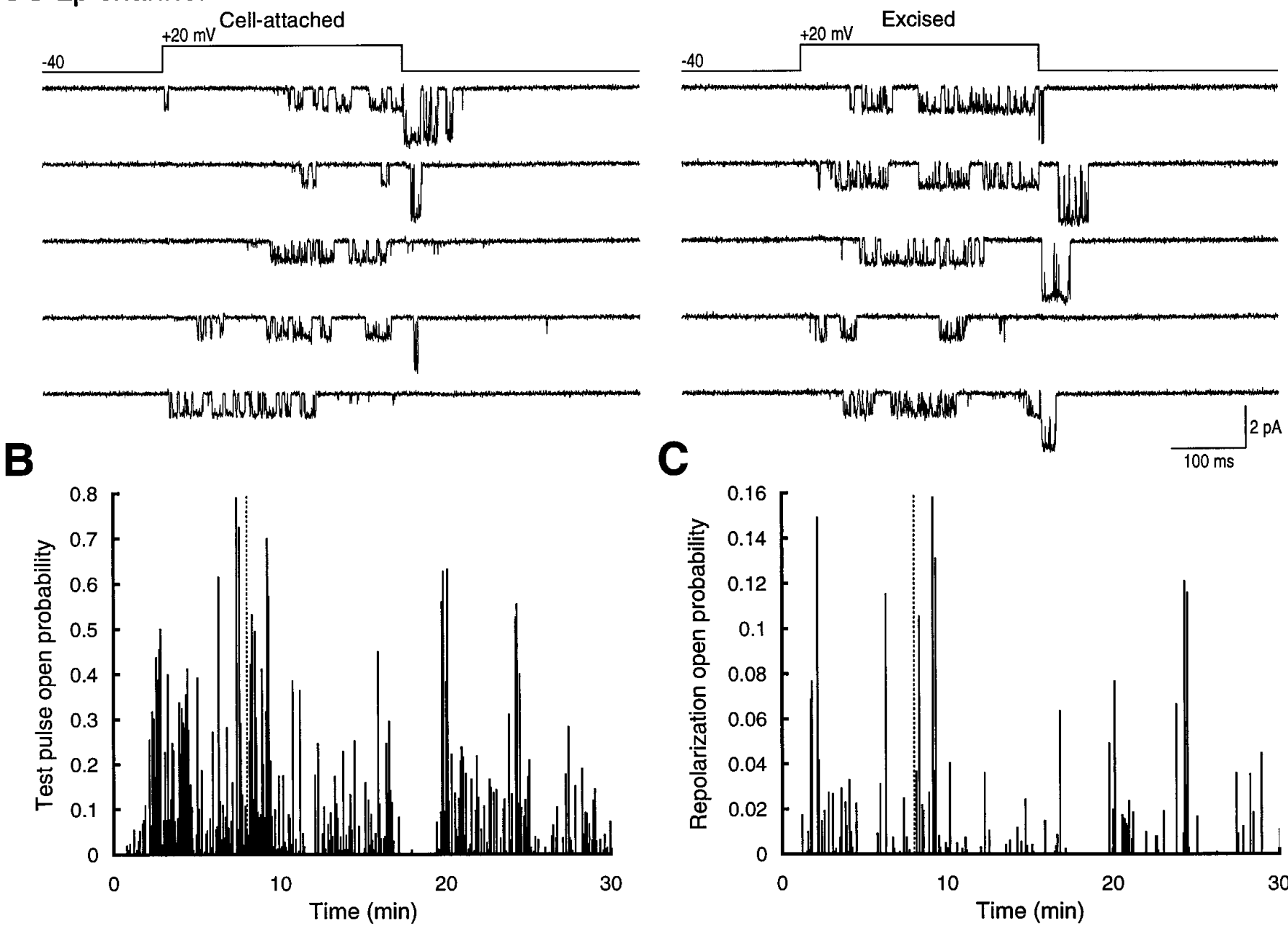

$\mathbf{D}$

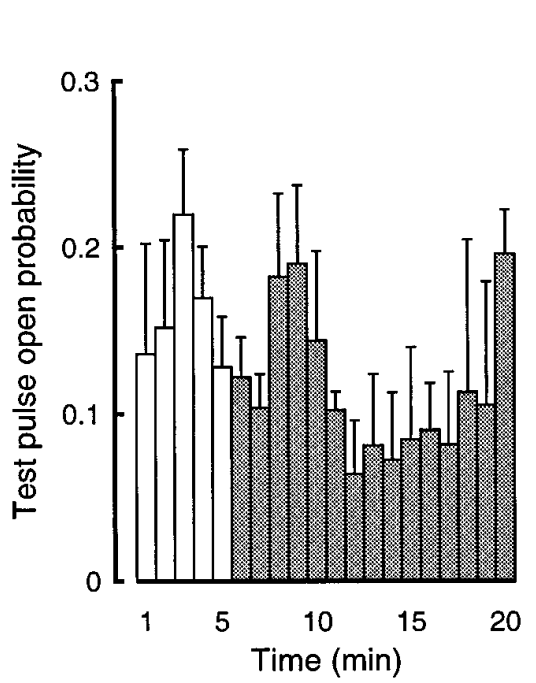

E
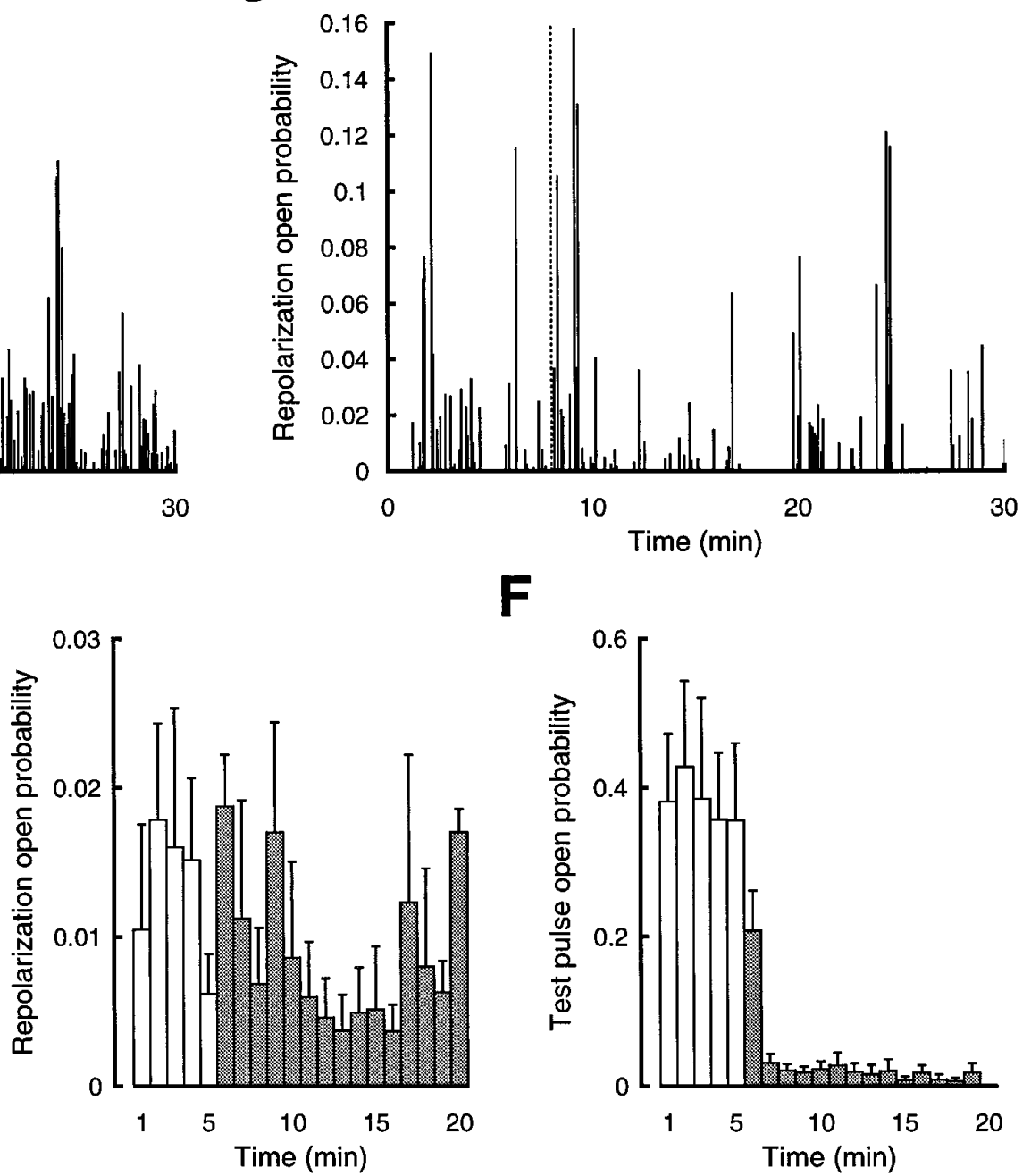

$\mathbf{F}$

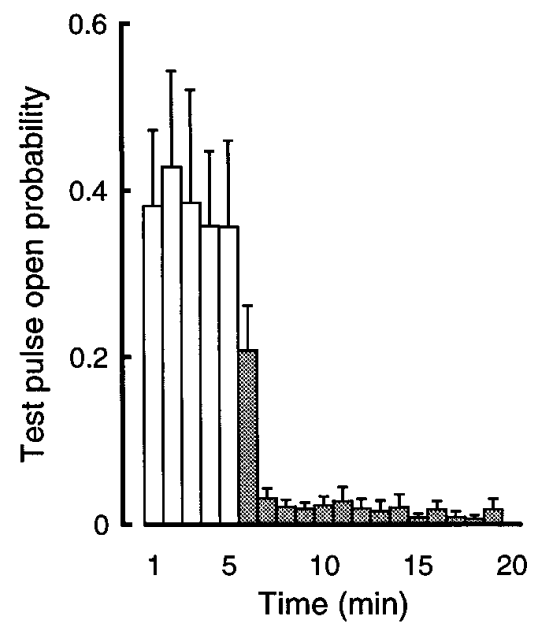

Figure 5. Lp channels retain their characteristic gating patterns in cell-free membrane patches. $A$, Five consecutive sweeps before (left) and after (right) excision of a patch containing a single $\mathrm{Lp}$ channel. $B$, Time course of Lp test pulse open probability at $+20 \mathrm{mV}$ from a holding potential of $-40 \mathrm{mV}$. The patch was excised $8 \mathrm{~min}$ into the recording (dashed line). Lp channel activity remained fairly stable over the course of the 30 min recording. $C$, Time course of $\mathrm{Lp}$ reopening probability during the same recording illustrated in $B$. Note that reopenings persisted during the $30 \mathrm{~min}$ period similar to that of test pulse activity. $D$, Binned and averaged data from recordings of $\mathrm{Lp}$ test pulse activity $(n=3$; for two of these the bath solution contained 4 mM ATP). Open bars indicate measurements taken before excision; shaded bars show measurement once the patch was excised. $E$, Same format as $D$, except for repolarization reopenings. $F$, Same format as $D$, expect for patches containing Ls channels $(n=10$; for five of these the bath solution contained 4 mM ATP). Note the rapid rundown compared with both Lp test pulse openings and Lp reopenings. 
Measurement of sweep-by-sweep open probability during the 30 min of the recording showed little decline for both test pulse and repolarization activity (Fig. $5 B, C$ ). When data from three experiments of this type were binned and averaged, in no case did we observe a separation of Lp potentiation from test pulse activity (Fig. 5D,E). In marked contrast to the rapid decline in Ls activity after excision (Fig. $5 F$ ), the resistance of the Lp channel to rundown was striking.

\section{$H-7$ and $H-89$}

To show that the responses to 8-CPT-cAMP were mediated by protein kinase activity and were not attributable to a direct effect on the calcium channel and to determine whether Lp reopenings could be blocked pharmacologically, we examined the effects of two kinase inhibitors, the broad spectrum inhibitor $\mathrm{H}-7$ and the relatively PKA-specific H-89 (Chijiwa et al., 1990). Because we were primarily interested in Lp potentiation, we restricted our analysis to $\mathrm{Lp}$ channel reopenings after repolarization. This enabled us to use multichannel patches in addition to singlechannel patches, because tail current reopenings exclusively represented the activity of $\mathrm{Lp}$ channels (Kavalali and Plummer, 1994).

Our first test was to assess the effectiveness of the kinase inhibitor H-89 by coapplying it with 8-CPT-cAMP. The concentration chosen was based on work by Ono and Fozzard (1993), which showed that $1 \mu \mathrm{M} \mathrm{H}-89$ prevented the action of okadaic acid on cardiac L-type calcium channels. We found in five experiments that this manipulation completely blocked the effect of the cAMP analog on $\mathrm{Lp}$ channels. Inspection of individual traces showed no differences between control cells and those exposed to both 8-CPT-cAMP and H-89 (Fig. 6 $A$; compare Lp reopening activity between the two conditions). There were also no remarkable differences in the time courses of the recordings, with both control and experimental cells having comparable rates of activity and rundown (Figs. 6B,C). These results were unlike what had been seen with 8-CPT-cAMP alone (Fig. $2 B$; compare Lp reopenings) and indicated that $\mathrm{H}-89$ was efficacious in this system.

We next looked at effects of $\mathrm{H}-89$ on cells taken from a single set of cultures and compared reopening probability under the following conditions: control, $1 \mathrm{~mm}$ 8-CPT-cAMP, 1 mM 8-CPT-cAMP plus $1 \mu \mathrm{M} \mathrm{H}-89$, and $1 \mu \mathrm{M} \mathrm{H}-89$ alone (Fig. $6 D)$. Compared with control recordings, $1 \mathrm{~mm}$ 8-CPT-cAMP significantly increased $L p$ reopening $(0.063 \pm 0.01$ vs $0.022 \pm$ $0.006 ; n=8$ and $7 ; p<0.01)$, whereas the combination of $1 \mathrm{~mm}$ 8-CPT-cAMP and $1 \mu \mathrm{M} \mathrm{H}-89$ showed reopenings comparable to control levels $(0.027 \pm 0.009 ; n=5 ; p>0.6)$. Treatment with H-89 alone produced no obvious effect, with patches again showing a reopening $p_{\mathrm{o}}$ value that was not distinguishable from control $(0.026 \pm 0.003 ; n=5 ; p>0.9)$. Parallel experiments with $100 \mu \mathrm{M} \mathrm{H}-7$ on a separate set of cultures produced comparable results (Fig. 6E); 8-CPT-cAMP enhanced the Lp reopening $p_{\mathrm{o}}(0.049 \pm 0.01$ vs $0.015 \pm 0.005 ; n=7$ and $4 ; p<$ $0.05)$, and this enhancement was abolished by coapplication of H-7 $(0.012 \pm 0.002 ; n=6 ; p>0.6)$. H-7 alone also had no effect $(0.015 \pm 0.007 ; n=2 ; p>0.15)$.

To complete our analysis of these data, we also obtained the mean dwell times of L p channel openings during repolarization under the different conditions. The averaged data from individual recordings can be summarized as follows: compared with control, the briefest component of open time $(1.34 \pm 0.23 \mathrm{msec})$ was not significantly different under all conditions tested (cAMP, $1.64 \pm$ $0.22 \mathrm{msec}$; cAMP plus $\mathrm{H}-89,2.0 \pm 0.33 \mathrm{msec}$; and $\mathrm{H}-89$ alone,
$1.7 \pm 0.38 \mathrm{msec})$. With the sole exception of the cAMP-treated cells, this was also true for the medium (control, $3.8 \pm 0.16$; cAMP, $5.86 \pm 0.8$; cAMP plus $\mathrm{H}-89,6 \pm 1.5$; and $\mathrm{H}-89$ alone, $5.8 \pm 1.0$ ) and long duration components (control, $15.4 \pm 3.4$; cAMP, $32.2 \pm 7.2$; cAMP plus H-89, $28.6 \pm 14.4$; and $\mathrm{H}-89$ alone, $25.3 \pm 4.5)$. None of the comparisons of the relative proportions of open time components was significant. Data summed from all recordings also showed no significant differences between conditions (Fig. $7 A ; p>0.05$, Kolmogorov-Smirnov test).

The set of experiments with the kinase inhibitor H-7 did not reveal any effects of the different treatments on open time or the open time distributions (Fig. $7 B ; p>0.05$, Kolmogorov-Smirnov test). For example, the medium duration component was similar for both control $(5.22 \pm 1.8)$ and cAMP $(5.18 \pm 0.4)$, was longer for $\mathrm{H}-7$ only $(7.04 \pm 2.9)$, and was shorter for cAMP plus $\mathrm{H}-7$ $(3.25 \pm 0.46)$. The long duration component was highest for cAMP $(32.5 \pm 7.0)$ compared with control $(19.4 \pm 1.4)$, cAMP plus $\mathrm{H}-7$ (21.3 \pm 2.9$)$, and $\mathrm{H}-7$ alone $(25.7 \pm 9.1)$.

From these experiments we concluded that application of $1 \mathrm{~mm}$ 8-CPT-cAMP increased the overall open probability of both $\mathrm{Lp}$ and Ls channels, and that this effect was attributable largely to increased availability rather than changes in open time durations or shifts between open states. We also showed that both inhibitors $\mathrm{H}-89$ and $\mathrm{H}-7$ were able to prevent the action of cAMP without having any obvious effects of their own. This stability of baseline activity indicated that the Lp potentiation observed under control conditions did not require phosphorylation by PKA or other $\mathrm{H}-7$-sensitive protein kinases. To follow up this point, we specifically examined the actions of H-7 on Lp potentiation.

\section{Effect of $\mathrm{H}$-7 on low- and high-voltage potentiation}

We have reported previously that there are two kinds of voltagedependent potentiation of Lp channel activity (Kavalali and Plummer, 1996), a type induced by low-voltage prepulses (LVP) and one induced by high-voltage prepulses (HVP). The results above suggest that the Lp potentiation does not require protein kinase activity, and we tested this idea explicitly with both singlechannel and whole-cell recordings using the same voltage protocols that were used to separate LVP and HVP.

For cell-attached single-channel recordings, a step pulse protocol was used in which Lp channel activity was measured during a $320 \mathrm{msec}$ test pulse at $-30 \mathrm{mV}$. The test pulse was immediately preceded by a $160 \mathrm{msec}$ conditioning prepulse of +40 or +120 $\mathrm{mV}$ to elicit LVP or LVP plus HVP, respectively. We conducted these experiments on cells that had been exposed to $100 \mu \mathrm{M} \mathrm{H}-7$ for at least $30 \mathrm{~min}$ before recording. This concentration of H-7 has been shown to block LTP (Malinow et al., 1989) and voltagedependent phosphorylation of facilitation channels in adrenal chromaffin cells (Artalejo et al., 1992). Under these conditions, LVP was clearly evident in single traces, revealed by numerous reopenings at $-30 \mathrm{mV}$ when the test pulse followed the conditioning pulse, but not in the test pulse alone (Fig. $8 \mathrm{~A}$, left and middle sets of sweeps). HVP was also observed in these experiments, seen as the appearance of exceptionally long duration openings at $-30 \mathrm{mV}$ when the test pulse followed a conditioning pulse of $+120 \mathrm{mV}$, but not after a conditioning pulse of $+40 \mathrm{mV}$ or alone (Fig. $8 A$, compare right set of sweeps to middle and left). Quantitative comparison of open probability in control cells with those pretreated with $\mathrm{H}-7$ showed no difference between the two conditions for either LVP (control, $0.028 \pm 0.01 ; n=8$; H-7, $0.03 \pm 0.003 ; n=5 ; p>0.8$ ) or HVP (control, $0.068 \pm 0.017 ; n=$ 8; H-7, $0.077 \pm 0.01 ; n=5 ; p>0.7$; Fig. $8 B$ ). 
A Lp channel

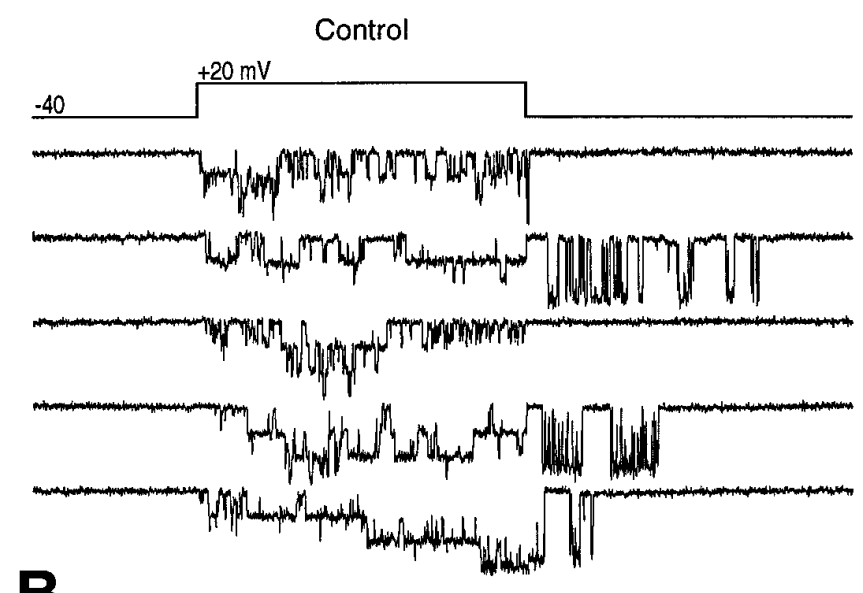

B

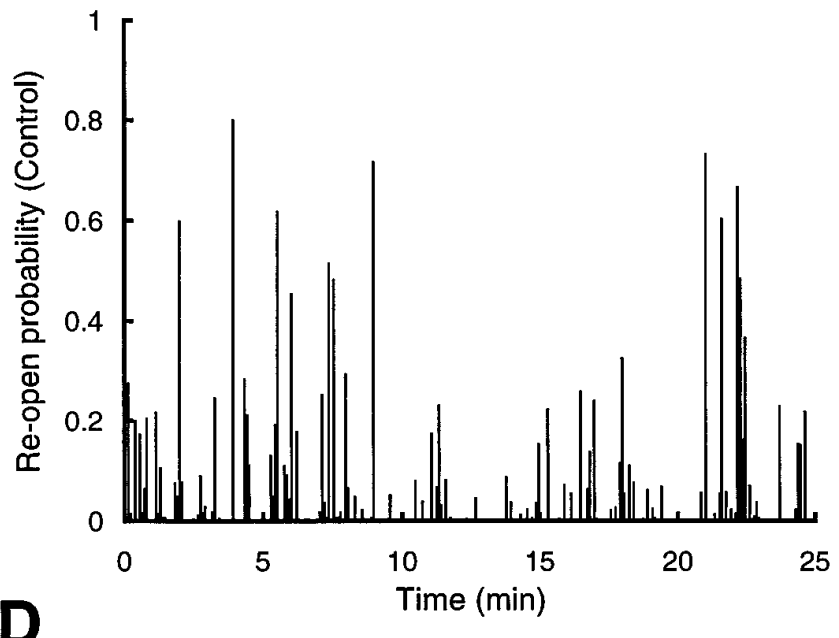

$\mathbf{D}$

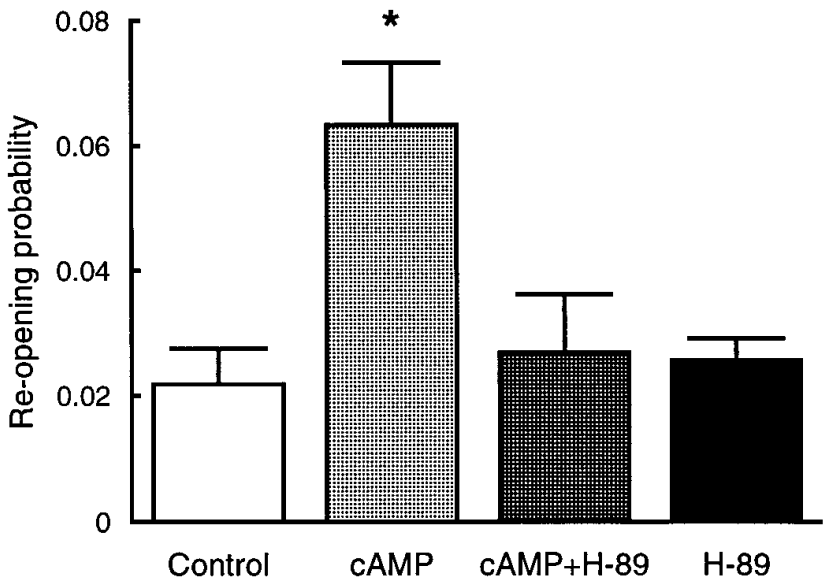

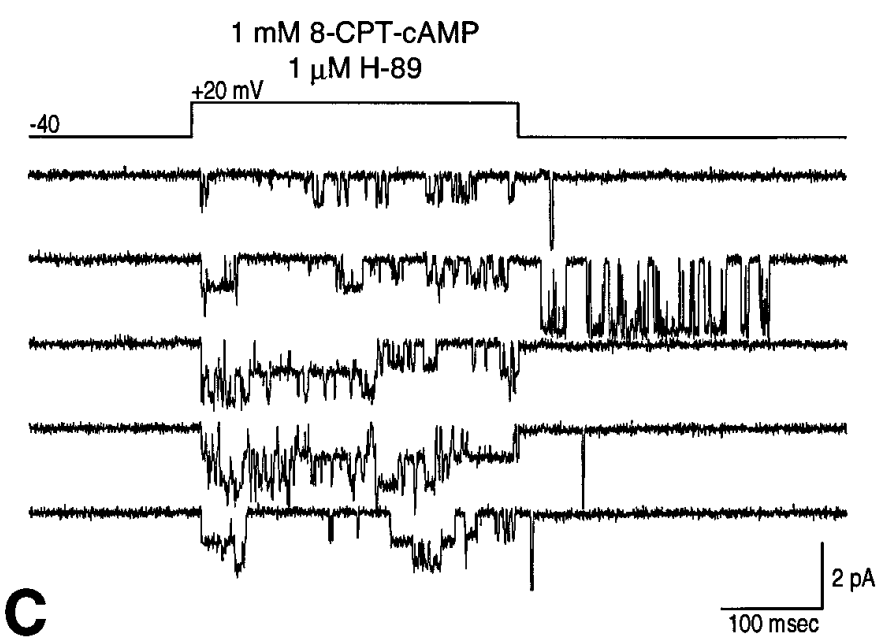

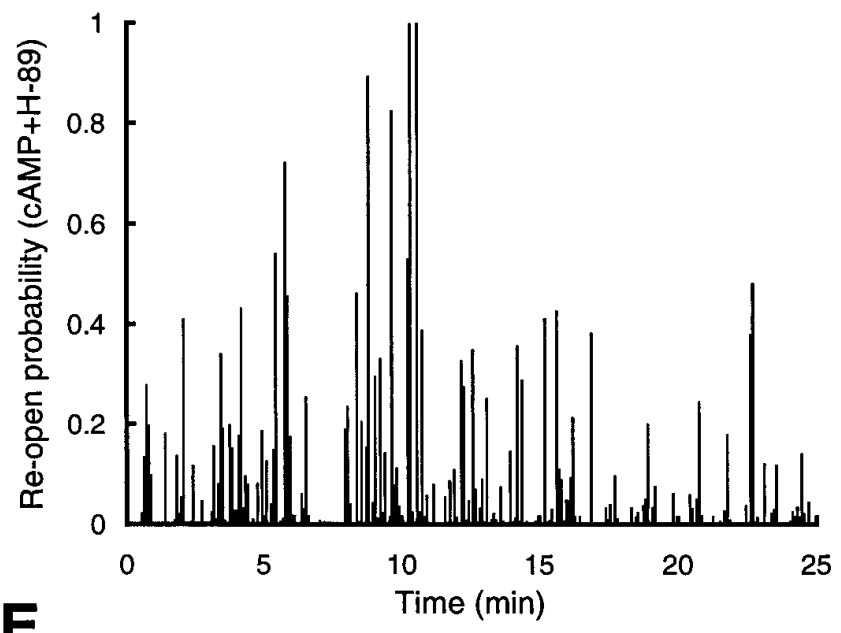

E

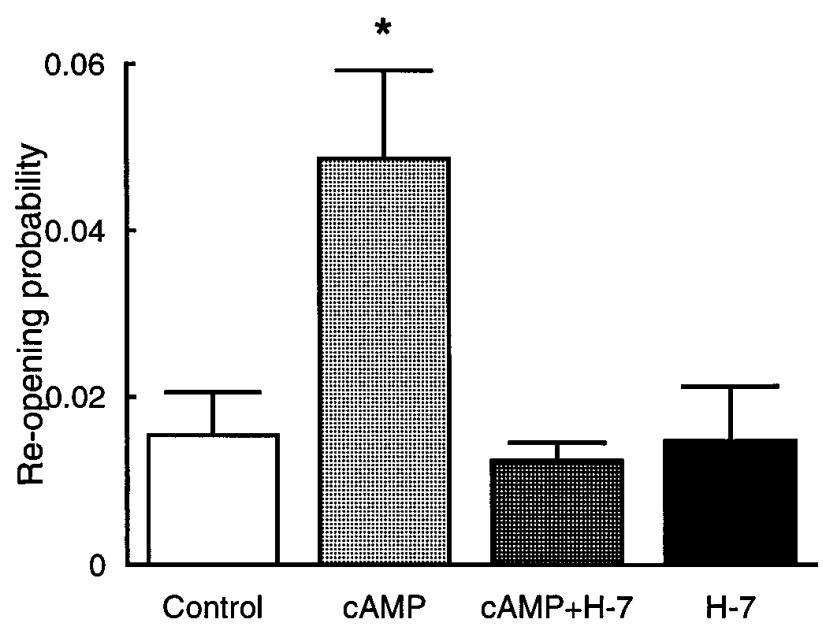

Figure 6. Protein kinase inhibitors H-89 and H-7 prevent effects of 8-CPT-cAMP but do not reduce baseline activity. $A$, Two sets of five consecutive sweeps of Lp channel activity from a control patch (left) and one that had been pretreated with 1 mM 8-CPT-cAMP plus $1 \mu \mathrm{M}$ H-89 (right). Both multichannel patches contained only one Lp channel, but the control patch contained three Ls channels, and the treated patch contained two Ls channels. Note that activity of the Lp channel in the patch on the right was similar to Lp activity in the patch on the left, unlike what occurred after treatment with $1 \mathrm{~mm}$ 8-CPT-cAMP alone (compare Lp reopenings in sweeps with the multichannel recording in Fig. $2 B$ ). $B$, $C$, Time course of Lp reopening probability for recordings illustrated in $A$. Note that activity in 8-CPT-cAMP plus H-89 $(C)$ was similar to that of control $(B)$. $D$, Probability of Lp reopenings under four different experimental conditions using $\mathrm{H}-89(n=7,8,5$, and 5 for control, 8-CPT-cAMP, 8-CPT-cAMP plus H-89, and H-89, respectively). $E$, Same format as $C$, except for $\mathrm{H}-7$ ( $n=4,7,6$, and 2 for control, 8-CPT-cAMP, 8-CPT-cAMP plus H-7, and H-7, respectively). Asterisks indicate significant differences $(p<0.05)$. 
A
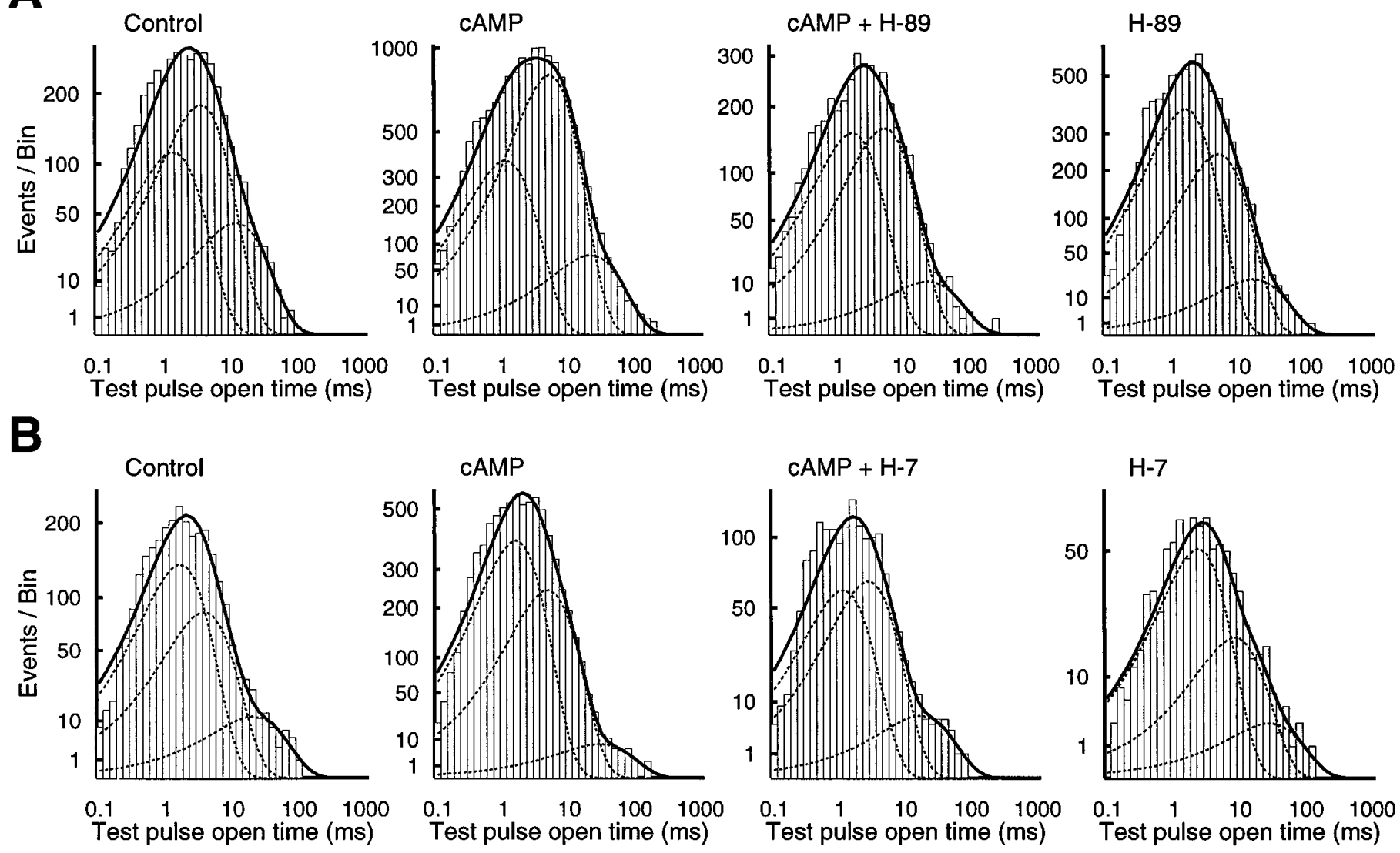

Figure 7. Open time distributions are not strongly affected by 8-CPT-cAMP or by the kinase inhibitors H-89 and H-7. A, Open time distribution for $\mathrm{Lp}$ channel reopenings under control and three experimental conditions: $1 \mathrm{mM}$ 8-CPT-cAMP, $1 \mathrm{mM}$ 8-CPT-cAMP plus $1 \mu \mathrm{M}$ H-89, and $1 \mu \mathrm{M} \mathrm{H}-89$. Recordings are the same as illustrated in Figure 6. B, H-7 experiments. The format is the same as $A$, except for the use of $100 \mu \mathrm{M} \mathrm{H}-7$.

To corroborate the single-channel data, we also made wholecell recordings in the absence of the DHP agonist used for channel identification in the cell-attached recordings. As described previously (Kavalali and Plummer, 1996), we evaluated both LVP and HVP from whole-cell recordings by measuring the amplitude of tail current at $-40 \mathrm{mV}$ after voltage pulses from -30 to $+100 \mathrm{mV}$. Measurement of tail current at a series of time points after repolarization was used to quantify the magnitude of LVP and HVP. The increase in the tail current amplitude at 5 msec after repolarization (which should exclude the non-DHPsensitive channels) showed a prominent biphasic rise (Fig. 8C). Based on correlation with our single-channel data, we have interpreted the early portion of the increase as LVP and the subsequent secondary rise as HVP (Kavalali and Plummer, 1996). Both components were present, despite the pretreatment with $\mathrm{H}-7$ at the same concentration that completely blocked the 8-CPT-cAMP effects seen in single-channel recordings and inclusion of $\mathrm{H}-7$ in the recording pipette. Measurements of tail current amplitude at later time points showed the expected decline in amplitude as well as the differential loss of HVP relative to LVP. Statistical comparison of the amplitude of peak current during the test pulse and three time points along the tail current showed no difference between control cells (peak, $157.5 \pm 24.5$ pA; $5 \mathrm{msec}, 58.7 \pm 8.4 \mathrm{pA} ; 10 \mathrm{msec}, 29.1 \pm 4.4 \mathrm{pA} ; 15 \mathrm{msec}$, $22.1 \pm 4.4 \mathrm{pA} ; n=16$ ) and those exposed to $\mathrm{H}-7$ (peak, $211 \pm$ $35.1 \mathrm{pA} ; 5 \mathrm{msec}, 54.8 \pm 10.6 \mathrm{pA} ; 10 \mathrm{msec}, 28.6 \pm 5.9 \mathrm{pA} ; 15 \mathrm{msec}$,
$19.1 \pm 4.1 \mathrm{pA} ; n=5 ; p>0.2,0.7,0.9$, and 0.6 , respectively; Fig. $8 D)$.

\section{DISCUSSION}

Stimulation of $\beta$-adrenergic receptors on cardiac muscle can significantly enhance cardiac contractility and heart rate by increasing calcium current (Reuter, 1965, 1966), an effect mediated through a cAMP-dependent pathway (Tsien et al., 1972; Reuter, 1974; Reuter and Scholz, 1977). $\beta$-Adrenergic receptors are coupled to a cholera toxin-sensitive GTP-binding protein $\left(\mathrm{G}_{\mathrm{s}}\right)$ that can stimulate adenylyl cyclase, leading to an increase in intracellular cAMP levels that promotes phosphorylation of cardiac L-type calcium channels by PKA (for review, see Trautwein and Hescheler, 1990; McDonald et al., 1994), although the exact site on the channel remains unknown (Charnet et al., 1995).

At the single-channel level, cAMP-dependent phosphorylation increases the likelihood that the channel will open during depolarization (Cachelin et al., 1983; Trautwein and Pelzer, 1988). This corresponds to a shift toward mode 1 from mode 0 in the scheme of Hess et al. (1984) and can be detected as an increase in the number of functional channels in a noise analysis of macroscopic currents (Bean et al., 1984). Additional experiments have also revealed an increase in the frequency of mode 2 openings of L-type channels in the presence of cAMP, indicating that phosphorylation can lead to a global redistribution of the time spent in different open states (Yue et al., 1990). 


\section{A Lp channel}

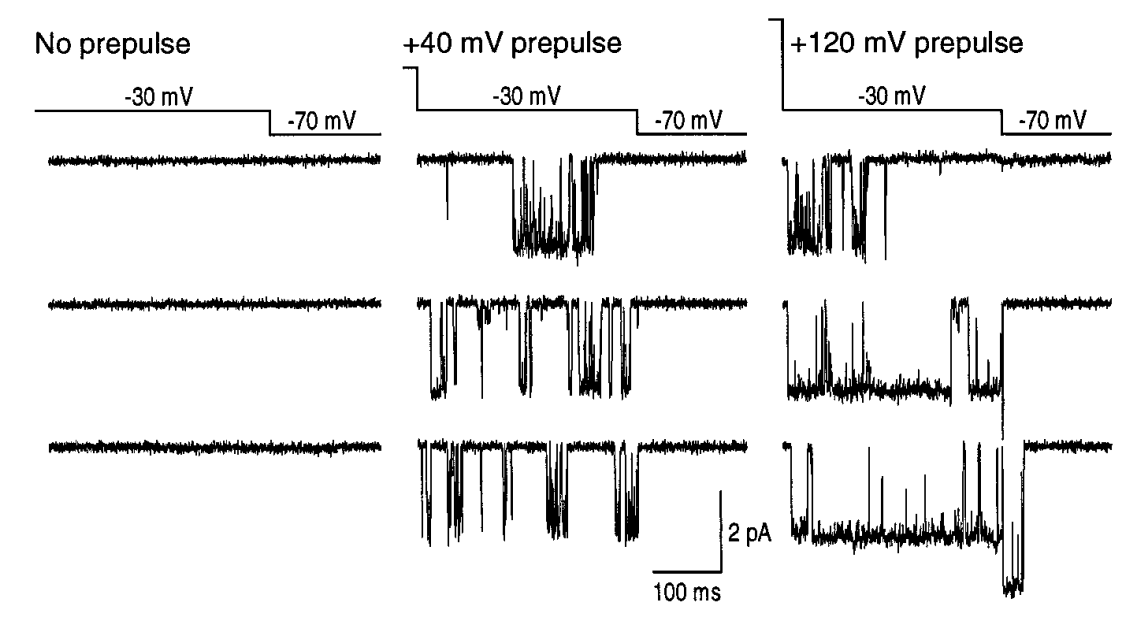

B

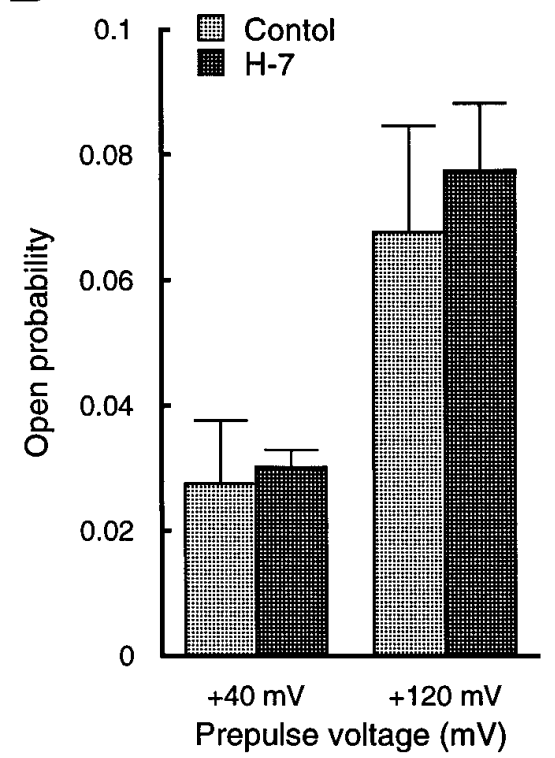

C

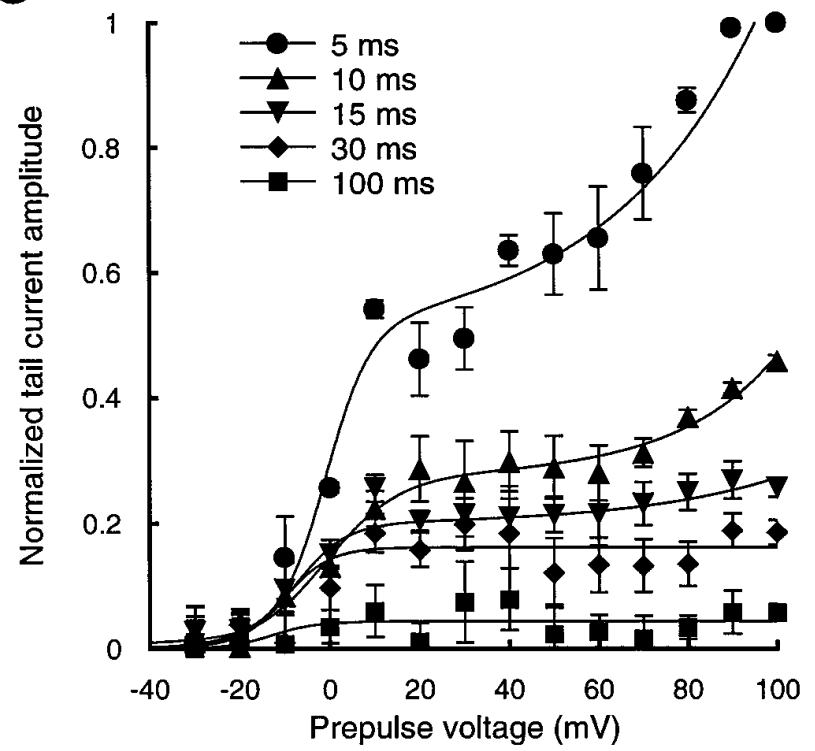

D

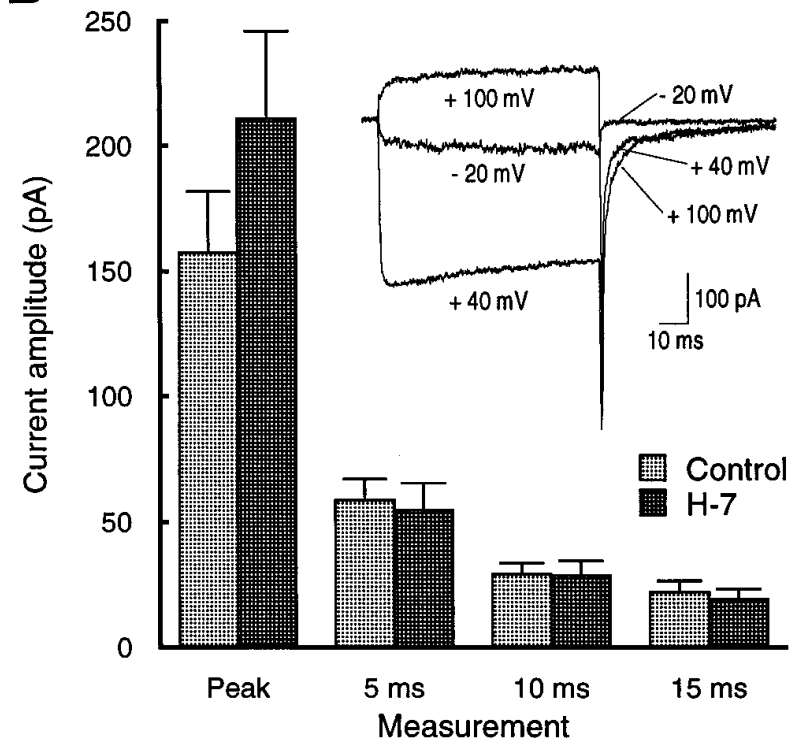

Figure 8. H-7 does not block low- or high-voltage Lp channel potentiation measured with single-channel or whole-cell recordings. $A$, Lp channel activity during a $-30 \mathrm{mV}$ test pulse alone (left) or after $160 \mathrm{msec}$ prepulses to $+40 \mathrm{mV}$ (middle) or $+120 \mathrm{mV}$ (right). The cell was treated with $100 \mu \mathrm{M} \mathrm{H}-7$ before this recording, and $\mathrm{H}-7$ was present in the bath during the recording. $B$, Average Lp open probability at $-30 \mathrm{mV}$ after prepulses to +40 or $+120 \mathrm{mV}$ in the absence (light bars; $n=6$ ) or presence (dark bars; $n=3$ ) of $\mathrm{H}-7$. Values were not significantly different for +40 or $+120 \mathrm{mV}(p>0.8$ and 0.7 , respectively). $C$, Plot of tail current amplitude versus prepulse potential at several time points after repolarization. For whole-cell recording, the pipette (intracellular) and bath solution both contained $100 \mu \mathrm{M} \mathrm{H}-7$. Tail current measurements began 5-10 min after breaking into a cell. Each point represents measurements from five recordings. Values were normalized for each experiment to the maximum tail current measured at the $5 \mathrm{msec}$ time point. Data points for each series were fit with the sum of a Boltzmann and exponential function. $D$, Comparison of the actual values of the peak current during the test pulse $(+40 \mathrm{mV})$ and tail currents at 5,10 , and $15 \mathrm{msec}$ after repolarization from experiments with $\mathrm{H}-7$ in the pipette $($ dark bars; $n=5)$ with control (light bars; $n=16$ ). Data were not significantly different ( $p>0.2,0.7,0.9$, and 0.6 for peak and 5,10 , and 15 msec, respectively). Inset, Representative whole-cell traces evoked by depolarizations to $-20,+40$, and $+100 \mathrm{mV}$ from a holding potential of $-40 \mathrm{mV}$ in the presence of $\mathrm{H}-7$. Control whole-cell data were those obtained from a previous study (Kavalali and Plummer, 1996).

Compared with the wealth of information available from cardiac cells, relatively little is known about the actions of PKA on neuronal L-type channels. Enhancement of hippocampal neuron calcium channel types after application of noradrenaline or isoprenaline has been found (Gray and Johnston, 1987; Fisher and Johnston, 1990), and recent work has suggested that this effect may constitute part of a positive feedback loop in which NMDA receptor-mediated increases in cAMP could augment further calcium influx by increasing the activity of voltage-gated calcium channels (Chetkovich et al., 1991).

The data presented in this paper have extended earlier work on cAMP-dependent enhancement of cardiac calcium channel availability to neurons and have shown that both the $\mathrm{Lp}$ and $\mathrm{Ls}$ subtypes of the DHP-sensitive calcium channel are affected. In 
hippocampal neurons, as in cardiac myocytes, the predominant effect was a reduction in null sweeps. When considering DHPsensitive calcium channels as members of a population, the greater availability not only would increase calcium influx for an individual channel, but would also lead to simultaneous opening of many channels. This larger overall percentage of active channels would enhance calcium entry, an effect that has been proposed to be important for transmitter release (Llinás et al., 1992; but see Stanley, 1993) and other processes sensitive to the concentration of subcellular levels of calcium.

We did not see any large changes in open times or their fractional distribution, either in averaged data from individual recordings or in summed data from all recordings. The absence of strong effects comparable to those seen in cardiac cells (Yue et al., 1990) may result from use of the DHP agonist, which already biases channel activity toward mode 2 openings. This did not compromise the main action of 8-CPT-cAMP, however, because the increase in availability was dramatic and robust under the conditions used in this study. Because of the extreme heterogeneity of calcium channels in central neurons (Regan et al., 1991; Mintz et al., 1992; Randall and Tsien, 1995), it was not feasible to do these experiments in the absence of an agonist and still be certain of channel identification. Explicit tests of kinetic mechanism must await cloning and expression of the Lp channel.

In bovine adrenal chromaffin cells, voltage-dependent potentiation of the "facilitation" channel can be blocked by the nonspecific protein kinase inhibitors $\mathrm{H}-7$ and K-252a (Artalejo et al., 1992) and induced by membrane-permeable analogs of cAMP (Artalejo et al., 1990). Taken together, these observations suggested that potentiation involved voltage-dependent phosphorylation of the facilitation channel (Artalejo et al., 1992). Our work with protein kinase inhibitors has shown that hippocampal neuron $\mathrm{Lp}$ potentiation does not work by a similar mechanism. Neither LVP nor HVP was blocked by H-7, and treatment with 8-CPT-cAMP caused a parallel increase in test pulse openings and repolarization reopenings. These results differ from those of Sculptoreanu et al. (1995), who found that activation of PKA was essential for potentiation of neuronal L-type channels. This may be attributable to the cell type studied, because their own work showed greater potentiation for parasympathetic neurons than dorsal root ganglion neurons, and potentiation may be different still in hippocampal neurons. Another possibility is that we were examining Lp channels, which may not be present in peripheral neurons, and we were using conditioning voltage pulses $(+40$ $\mathrm{mV}$ ) that were substantially lower than those used by Sculptoreanu et al. $(+100 \mathrm{mV})$. Our data agree, however, with studies of cloned neuronal (Bourinet et al., 1994) and smooth muscle $\alpha_{1 \mathrm{C}}$ (Kleppisch et al., 1994) channels, which did not find evidence of voltage-dependent phosphorylation essential to potentiation.

In addition to modulation by cAMP, two new facets of $\mathrm{Lp}$ channel activity were revealed by the present study. First, Lp channels were much less sensitive to excision than Ls channels. As expected, Ls channel activity rapidly declined under cell-free conditions; Lp channels continued opening for many minutes, however, despite separation from the cytoplasm. From this, it may be possible to conclude that Lp activity is less dependent on phosphorylation than Ls activity. It is also plausible, however, that the Lp channel has a tightly associated constitutively active kinase that maintains its activity such as in calcium-activated potassium channels (Chung et al., 1991; for review, see MochlyRosen, 1995). Although it is not clear why the Lp channel should be resistant to excision when the Ls channel is not, one possible consequence of this may be that the Lp channel would still be active under conditions of metabolic stress such as hypoxia. Because there is some evidence of the involvement of DHPsensitive channels in neurotoxic cell death (Weiss et al., 1990), it may be that the $\mathrm{Lp}$ channel is primarily responsible, because the Ls channel would be expected to be silent after depletion of ATP.

A second noteworthy observation is that the characteristic gating patterns of the Lp and Ls channels were stable in all experiments regardless of excision or the presence of 8-CPTcAMP. It is not yet known whether Lp channels are truly distinct from the Ls channels or whether $\mathrm{Lp}$ activity represents a longlived Ls gating mode. The absence of $\mathrm{Lp}$ to Ls interconversions, even in the presence of 8-CPT-cAMP, which increased Ls and $\mathrm{Lp}$ activity, as well as the differential rate of rundown, adds support for the idea that the two kinds of channels are different. This is certainly reasonable given that diverse transcripts generated by alternate splicing can differ in properties such as DHP inhibition (Soldatov et al., 1995) and even the recent observation that different calcium channel size forms can be dynamically constructed (Hell et al., 1995).

The ubiquitous nature of calcium signaling (for review, see Clapham, 1995; Ghosh and Greenberg, 1995) suggests numerous possible functions for $\mathrm{Lp}$ and Ls channel modulation by cAMP. Anatomical evidence indicates that DHP-sensitive calcium channels are localized to dendritic spines and cell bodies (Westenbroek et al., 1990; Hell et al., 1993, 1995), and calcium influx through DHP-sensitive calcium channels can stimulate growth factor receptor signal transduction (Rosen et al., 1996), can affect cell migration (Moran, 1991), may contribute to aging-related disorders (Thompson et al., 1990; Landfield, 1994; Thibault and Landfield, 1996), and can initiate expression of immediate early genes (Murphy et al., 1991; Bading et al., 1993; Thompson et al., 1995).

At present, most evidence suggests that non-DHP-sensitive channels provide the presynaptic calcium influx that triggers neurotransmitter release from central neurons (Turner et al., 1992; Turner et al., 1993; Regehr and Mintz, 1994; Wheeler et al., 1994; Dunlap et al., 1995; Elliott et al., 1995; Scholz and Miller, 1995), although DHP-sensitive channels may participate in dendritic release (Simmons et al., 1995). This does not mean, however, that L-type calcium channels are not involved in the modulation of synaptic strength. DHP-sensitive calcium channels have been implicated in mossy fiber long-term potentiation (for review, see Johnston et al., 1992) and in a short-term form of postsynaptic potentiation (Kullmann et al., 1992; Wyllie et al., 1994). Enhancement of Lp or Ls activity by cAMP could work in concert with other PKA-dependent mechanisms that increase synaptic strength, such as phosphorylation of neurotransmitter receptors (Blackstone et al., 1994; Raman et al., 1996).

An interesting feature of the L channel is that the potentiated openings have a voltage dependence that is quite different from that of the unpotentiated channel (Kavalali and Plummer, 1996). This could mean that recently described calcium channel openings that occur in response to subthreshold synaptic inputs (Markram and Sakmann, 1994; Magee and Johnston, 1995) as well as DHP-sensitive calcium currents at resting membrane potentials (Avery and Johnston, 1996; Magee et al., 1996) may also involve the potentiated $\mathrm{Lp}$ channel. This channel has a much larger conductance than the T-type channel, and because its activity can be modulated by PKA, stimuli that cause the Lp channel to enter its potentiated state may produce significant calcium influx even when at subthreshold voltages. This becomes more significant when one considers the increased driving force 
at negative potentials and that the decline in $\mathrm{Lp}$ potentiation occurs more slowly than T-type channel deactivation.

\section{REFERENCES}

Anwyl R (1991) Modulation of vertebrate neuronal calcium channels by transmitters. Brain Res Rev 16:265-281.

Artalejo CR, Ariano MA, Perlman RL, Fox AP (1990) Activation of facilitation calcium channels in chromaffin cells by $\mathrm{D}_{1}$ dopamine receptors through a cAMP/protein kinase A-dependent mechanism. Nature 348:239-242.

Artalejo CR, Dahmer MK, Perlman RL, Fox AP (1991a) Two types of $\mathrm{Ca}^{2+}$ currents are found in bovine chromaffin cells: facilitation is due to the recruitment of one type. J Physiol (Lond) 432:681-707.

Artalejo CR, Mogul DJ, Perlman RL, Fox AP (1991b) Three types of bovine chromaffin cell $\mathrm{Ca}^{2+}$ channels: facilitation increases the opening probability of a $27 \mathrm{pS}$ channel. J Physiol (Lond) 444:213-240.

Artalejo CR, Rossie S, Perlman RL, Fox AP (1992) Voltage-dependent phosphorylation may recruit $\mathrm{Ca}^{2+}$ current facilitation in chromaffin cells. Nature 358:63-66.

Avery RB, Johnston D (1996) Multiple channel types contribute to the low-voltage-activated calcium current in hippocampal CA3 pyramidal neurons. J Neurosci 16:5567-5582.

Bading H, Ginty DD, Greenberg ME (1993) Regulation of gene expression in hippocampal neurons by distinct calcium signaling pathways. Science 260:181-186.

Bean BP, Nowycky MC, Tsien RW (1984) Beta-adrenergic modulation of calcium channels in frog ventricular heart cells. Nature 307:371-375

Blackstone C, Murphy TH, Moss SJ, Baraban JM, Huganir RL (1994) Cyclic AMP and synaptic activity-dependent phosphorylation of AMPA-preferring glutamate receptors. J Neurosci 14:7585-7593.

Bourinet E, Charnet P, Tomlinson WJ, Stea A, Snutch TP, Nargeot J (1994) Voltage-dependent facilitation of a neuronal alpha 1C L-type calcium channel. EMBO J 13:5032-5039.

Cachelin AB, dePeyer JE, Kokubun S, Reuter H (1983) Calcium channel modulation by 8-bromo-cyclic AMP in cultured heart cells. Nature 304:402-404.

Charnet P, Lory P, Bourinet E, Collin T, Nargeot J (1995) cAMPdependent phosphorylation of the cardiac L-type channel: a missing link?. Biochimie 77:957-962.

Chetkovich DM, Gray R, Johnston D, Sweatt JD (1991) N-Methyl-Daspartate receptor activation increases cAMP levels and voltage-gated $\mathrm{Ca}^{2+}$ channel activity in area CA1 of hippocampus. Proc Natl Acad Sci USA 88:6467-6471.

Chijiwa T, Mishima A, Hagiwara M, Sano M, Hayashi K, Inoue T, Naito K, Toshioka T, Hidaka H (1990) Inhibition of forskolin-induced neurite outgrowth and protein phosphorylation by a newly synthesized selective inhibitor of cyclic AMP-dependent-protein kinase, $N-[2-(p-$ bromocinnamylamino)ethyl]-5-isoquinolinesulfonamide (H-89), of PC12D pheochromocytoma cells. J Biol Chem 265:5267-5272.

Chung S, Reinhart PH, Martin BL, Brautigan D, Levitan IB (1991) Protein kinase activity closely associated with a reconstituted calciumactivated potassium channel. Science 253:560-562.

Clapham D (1995) Calcium signaling. Cell 80:259-268.

Colquhoun D, Sigworth FJ (1983) Fitting and statistical analysis of single-channel records. In: Single-channel recording (Sakmann B, Neher E, eds), pp 191-263. New York: Plenum.

Dunlap K, Luebke JI, Turner TJ (1995) Exocytotic $\mathrm{Ca}^{2+}$ channels in mammalian central neurons. Trends Neurosci 18:89-98.

Elliott EM, Malouf AT, Catterall WA (1995) Role of calcium channel subtypes in calcium transients in hippocampal CA3 neurons. J Neurosci 15:6433-6444.

Elmslie SK, Zhou W, Jones SW (1990) LHRH and GTP- $\gamma$-S modify calcium current activation in bullfrog sympathetic neurons. Neuron 5:75-80.

Fenwick EM, Marty A, Neher E (1982) Sodium and calcium channels in bovine chromaffin cells. J Physiol (Lond) 331:599-635.

Fisher R, Johnston D (1990) Differential modulation of single voltagegated calcium channels by cholinergic and adrenergic agonists in adult hippocampal neurons. J Neurophysiol 64:1291-1300.

Foehring RC (1996) Serotonin modulates N- and P-type calcium currents in neocortical pyramidal neurons via a membrane-delimited pathway. J Neurophysiol 75:648-659.

Foley CF, Pelzer DJ (1994) Voltage-dependent recruitment of $\mathrm{Ca}^{2+}$ current facilitation in isolated ventricular myocytes from guinea-pig heart. J Physiol (Lond) 477:88-89P.
Forscher P, Oxford GS (1985) Modulation of calcium channels by norepinephrine in internally dialyzed avian sensory neurons. J Gen Physiol 85:743-763.

Ghosh A, Greenberg ME (1995) Calcium signaling in neurons: molecular mechanisms and cellular consequences. Science 268:239-247.

Gray R, Johnston D (1987) Noradrenaline and $\beta$-adrenoceptor agonists increase activity of voltage-dependent calcium channels in hippocampal neurons. Nature 327:620-622.

Hell JW, Westenbroek RE, Warner C, Ahlijanian MK, Prystay W, Gilbert MM, Snutch TP, Catterall WA (1993) Identification and differential subcellular localization of the neuronal class C and class D L-type calcium channel alpha 1 subunits. J Cell Biol 123:949-962.

Hell JW, Westenbroek RE, Breeze LJ, Wang KKW, Chavkin C, Catterall WA (1995) $N$-Methyl-D-aspartate receptor-induced proteolytic conversion of postsynaptic class C L-type calcium channels in hippocampal neurons. Proc Natl Acad Sci USA 93:3362-3367.

Hess P, Lansman JB, Tsien RW (1984) Different modes of Ca channel gating behaviour favoured by dihydropyridine $\mathrm{Ca}$ agonists and antagonists. Nature 311:538-544.

Hille B (1994) Modulation of ion-channel function by G-protein-coupled receptors. Trends Neurosci 17:531-536.

Hoshi T, Smith SJ (1987) Large depolarization induces long openings of voltage-dependent calcium channels in adrenal chromaffin cells. J Neurosci 7:571-580.

Ikeda SR (1991) Double-pulse calcium channel current facilitation in adult rat sympathetic neurones. J Physiol (Lond) 439:181-214.

Johnson BD, Byerly L (1994) $\mathrm{Ca}^{2+}$ channel $\mathrm{Ca}^{2+}$-dependent inactivation in a mammalian central neuron involves the cytoskeleton. Pflugers Arch 429:14-21.

Johnston D, Williams S, Jaffe D, Gray R (1992) NMDA-receptorindependent long-term potentiation. Annu Rev Physiol 54:489-505.

Kasai H (1991) Tonic inhibition and rebound facilitation of a neuronal calcium channel by GTP-binding protein. Proc Natl Acad Sci USA 88:8855-8859.

Kavalali ET, Plummer MR (1994) Selective potentiation of a novel calcium channel in rat hippocampal neurones. J Physiol (Lond) 480:475-484.

Kavalali ET, Plummer MR (1996) Multiple voltage-dependent mechanisms potentiate calcium channel activity in hippocampal neurons. J Neurosci 16:1072-1082.

Kleppisch T, Pedersen K, Strubing C, Bosse-Doenecke E, Flockerzi V, Hofmann F, Hescheler J (1994) Double-pulse facilitation of smooth muscle $\alpha_{1}$-subunit $\mathrm{Ca}^{2+}$ channels expressed in CHO cells. EMBO J 13:2502-2507.

Kullmann DM, Perkel DJ, Manabe T, Nicoll RA (1992) $\mathrm{Ca}^{2+}$ entry via postsynaptic voltage-sensitive $\mathrm{Ca}^{2+}$ channels can transiently potentiate excitatory synaptic transmission in the hippocampus. Neuron 9:1175-1183.

Landfield PW (1994) Increased hippocampal $\mathrm{Ca}^{2+}$ channel activity in brain aging and dementia. Hormonal and pharmacologic modulation. Ann NY Acad Sci 747:351-364.

Lipscombe D, Kongsamut S, Tsien RW (1989) $\alpha$-Adrenergic inhibition of sympathetic neurotransmitter release mediated by modulation of N-type calcium channel gating. Nature 340:639-642.

Llinás R, Sugimori M, Silver RB (1992) Microdomains of high calcium concentration in a presynaptic terminal. Science 256:677-679.

Lu B, Yokoyama M, Dreyfus CF, Black IB (1991) NGF gene expression in actively growing brain glia. J Neurosci 11:318-326.

Magee JC, Johnston D (1995) Synaptic activation of voltage-gated channels in the dendrites of hippocampal pyramidal neurons. Science 268:301-304.

Magee JC, Avery RB, Christie BR, Johnston D (1996) Dihydropyridinesensitive, voltage-gated $\mathrm{Ca}^{2+}$ channels contribute to the resting intracellular $\mathrm{Ca}^{2+}$ concentration of hippocampal CA1 pyramidal neurons. J Neurophysiol 76:3460-3470.

Malinow R, Schulman H, Tsien RW (1989) Inhibition of postsynaptic PKC or CaMKII blocks induction but not expression of LTP. Science 245:862-245.

Markram H, Sakmann B (1994) Calcium transients in dendrites of neocortical neurons evoked by single subthreshold excitatory postsynaptic potentials via low-voltage-activated calcium channels. Proc Natl Acad Sci USA 91:5207-5211.

McDonald TF, Pelzer S, Trautwein W, Pelzer D (1994) Regulation and modulation of calcium channels in cardiac, skeletal, and smooth muscle cells. Physiol Rev 74:365-507. 
Mintz IM, Adams ME, Bean BP (1992) P-type calcium channels in rat central and peripheral neurons. Neuron 9:85-95.

Mochly-Rosen D (1995) Localization of protein kinases by anchoring proteins: a theme in signal transduction. Science 268:247-251.

Moran D (1991) Voltage-dependent L-type $\mathrm{Ca}^{2+}$ channels participate in regulating neural crest migration and differentiation. Am J Anat 192:14-22.

Murphy TH, Worley PF, Baraban JM (1991) L-type voltage-sensitive calcium channels mediate synaptic activation of immediate early genes. Neuron 7:625-635.

Ono K, Fozzard HA (1993) Two phosphatase sites on the $\mathrm{Ca}^{2+}$ channel affecting different kinetic functions. J Physiol (Lond) 470:73-84.

Pietrobon D, Hess P (1990) Novel mechanism of voltage-dependent gating in L-type calcium channels. Nature 346:651-655.

Raman IM, Tong G, Jahr CE (1996) $\beta$-adrenergic regulation of synaptic NMDA receptors by cAMP-dependent protein kinase. Neuron 16:415-421.

Randall A, Tsien RW (1995) Pharmacological dissection of multiple types of $\mathrm{Ca}^{2+}$ channel currents in rat cerebellar granule neurons. J Neurosci 15:2995-3012.

Regan LJ, Sah DW, Bean BP (1991) $\mathrm{Ca}^{2+}$ channels in rat central and peripheral neurons: high-threshold current resistant to dihydropyridine blockers and omega-conotoxin. Neuron 6:269-280.

Regehr WG, Mintz IM (1994) Participation of multiple calcium channel types in transmission at single climbing fiber to Purkinje cell synapses. Neuron 12:605-613.

Reuter H (1965) Über die wirkung von adrenalin auf den cellulären Ca-umsatz des meerschweinchenvorhofs. Naunyn Schmiedebergs Arch Pharmacol 251:401-412.

Reuter H (1966) Strom-spannungsbeziehungen von purkinje-fasern bei verschiedenen extracellulären calcium-Konzentrationen und unter adrenalineinwirkung. Pflugers Arch 287:357-367.

Reuter H (1974) Localization of beta adrenergic receptors, and effects of noradrenaline and cyclic nucleotides on action potentials, ionic currents and tension in mammalian cardiac muscle. $\mathbf{J}$ Physiol (Lond) 242:429-451.

Reuter H, Scholz H (1977) The regulation of the calcium conductance of cardiac muscle by adrenaline. J Physiol (Lond) 264:49-62.

Rosen LB, Greenberg ME (1996) Stimulation of growth factor receptor signal transduction by activation of voltage-sensitive calcium channels. Proc Natl Acad Sci USA 93:1113-1118.

Scholz KP, Miller RJ (1991) Analysis of adenosine actions on $\mathrm{Ca}^{2+}$ currents and synaptic transmission in cultured rat hippocampal pyramidal neurones. J Physiol (Lond) 435:373-393.

Scholz KP, Miller RJ (1995) Developmental changes in presynaptic calcium channels coupled to glutamate release in cultured rat hippocampal neurons. J Neurosci 15:4612-4617.

Sculptoreanu A, Rotman E, Takahashi M, Scheuer T, Catterall WA (1993a) Voltage-dependent potentiation of the activity of cardiac L-type calcium channel alpha 1 subunits due to phosphorylation by cAMP-dependent protein kinase. Proc Natl Acad Sci USA 90:10135-10139.

Sculptoreanu A, Scheuer T, Catterall WA (1993b) Voltage-dependent potentiation of L-type $\mathrm{Ca}^{2+}$ channels due to phosphorylation by cAMP-dependent protein kinase. Nature 364:240-243.

Sculptoreanu A, Figourov A, De Groat WC (1995) Voltage-dependent potentiation of neuronal L-type calcium channels due to statedependent phosphorylation. Am J Physiol 269:C725-C732.

Sigworth FJ, Sine SM (1987) Data transformations for improved display and fitting of single-channel dwell time histograms. Biophys $\mathbf{J}$ 52:1047-1054.

Simmons ML, Terman GW, Gibbs SM, Chavkin C (1995) L-type calcium channels mediate dynorphin neuropeptide release from dendrites but not axons of hippocampal granule cells. Neuron 14:1265-1272.

Soldatov NM, Bouron A, Reuter H (1995) Different voltage-dependent inhibition by dihydropyridines of human $\mathrm{Ca}^{2+}$ channel splice variants. J Biol Chem 270:10540-10543.

Stanley EF (1993) Single calcium channels and acetylcholine release at a presynaptic nerve terminal. Neuron 11:1007-1011.

Thibault O, Landfield PW (1996) Increase in single L-type calcium channels in hippocampal neurons during aging. Science 272:1017-1020.

Thompson LT, Deyo RA, Disterhoft JF (1990) Nimodipine enhances spontaneous activity of hippocampal pyramidal neurons in aging rabbits at a dose that facilitates associative learning. Brain Res 535:119-130.

Thompson MA, Ginty DD, Bonni A, Greenberg ME (1995) L-type voltage-sensitive $\mathrm{Ca}^{2+}$ channel activation regulates c-fos transcription at multiple levels. J Biol Chem 270:4224-4235.

Toth PT, Bindokas VP, Bleakman D, Colmers WF, Miller RJ (1993) Mechanism of presynaptic inhibition by neuropeptide $\mathrm{Y}$ at sympathetic nerve terminals. Nature 364:635-639.

Trautwein W, Hescheler J (1990) Regulation of cardiac L-type calcium current by phosphorylation and $\mathrm{G}$ proteins. Annu Rev Physiol. 52:257-274.

Trautwein W, Pelzer D (1988) Kinetics, and $\beta$-adrenergic modulation of cardiac $\mathrm{Ca}^{2+}$ channels. In: The calcium channel: structure, function and implications (Morad M, Nayler W, Kazda S, Schramm M, eds), pp 39-53. Heidelberg: Springer.

Tsien RW, Giles W, Greengard P (1972) Cyclic AMP mediates the effects of adrenaline on cardiac purkinje fibers. Nat New Biol 240:181-183.

Turner TJ, Adams ME, Dunlap K (1992) Calcium channels coupled to glutamate release identified by $\omega$-Aga-IVA. Science 258:310-313.

Turner TJ, Adams ME, Dunlap K (1993) Multiple $\mathrm{Ca}^{2+}$ channel types coexist to regulate synaptosomal neurotransmitter release. Proc Natl Acad Sci USA 90:9518-9522.

Weiss JH, Hartley DM, Koh J, Choi DW (1990) The calcium channel blocker nifedipine attenuates slow excitatory amino acid neurotoxicity. Science 247:1474-1477.

Westenbroek RE, Ahlijanian MK, Catterall WA (1990) Clustering of L-type $\mathrm{Ca}^{2+}$ channels at the base of major dendrites in hippocampal pyramidal neurons. Nature 347:281-284.

Wheeler DB, Randall A, Tsien RW (1994) Roles of N-type and Q-type $\mathrm{Ca}^{2+}$ channels in supporting hippocampal synaptic transmission. Science 264:107-111.

Wyllie DJA, Manabe T, Nicoll RA (1994) A rise in postsynaptic $\mathrm{Ca}^{2+}$ potentiates miniature excitatory postsynaptic currents and AMPA responses in hippocampal neurons. Neuron 12:127-138.

Yue DT, Herzig S, Marban E (1990) $\beta$-Adrenergic stimulation of calcium channels occurs by potentiation of high-activity gating modes. Proc Natl Acad Sci USA 87:753-757. 